\title{
Spatial distribution of cold-season lightning frequency in the coastal areas of the Sea of Japan
}

\author{
Daiki Tsurushima ${ }^{1 *}$, Kiyotaka Sakaida ${ }^{2}$ and Noriyasu Honma ${ }^{3}$
}

\begin{abstract}
The coastal areas of the Sea of Japan are a well-known hotspot of winter lightning activity. This study distinguishes between three common types of winter lightning in that region (types $\mathrm{A}-\mathrm{C}$ ), based on their frequency distributions and the meteorological conditions under which they occur. Type A lightning occurs with high frequency in the Tohoku district. It is mainly caused by cold fronts that accompany cyclones passing north of the Japanese islands. Type B, which occurs most frequently in the coastal areas of the Hokuriku district, is mainly caused by topographically induced wind convergence and convective instability, both of which are associated with cyclones having multiple centers. Type C's lightning frequency distribution pattern is similar to that of type B, but its principal cause is a topographically induced wind convergence generated by cold air advection from the Siberian continent. Type A is most frequently observed from October to November, while types B and $C$ tend to appear from November to January, consistent with seasonal changes in lightning frequency distribution in Japan's Tohoku and Hokuriku districts.
\end{abstract}

Keywords: Lightning, LLS, Cluster analysis, Climatology

\section{Background}

The coastal areas of the Sea of Japan are among the most widely known winter lightning activity hotspots in the world (Rakov and Uman 2007). Since winter lightning contains more electrically intensive discharges than summer lightning (Brook et al. 1982; Hojo et al. 1989; Ishii et al. 2012), it often causes serious damage to electrical equipment (transmission lines, wind turbines, etc.).

In Japan, district-wide lightning detection networks have been in place since the 1990s. These networks, generally called lightning location systems (LLS), are able to make highly accurate measurements of lightning geo-locations and the time of lightning occurrences.

LLSs have made it possible to examine detailed patterns of winter lightning activity in the coastal areas of the Sea of Japan. For example, Fujisawa and Kawamura (2005) clarified lightning frequency distributions and seasonal changes (Nov.-Feb.) based on 9 years of data obtained by the LLS in the Hokuriku district. Their results indicated

\footnotetext{
* Correspondence: daikitsurushima@gmail.com

${ }^{1}$ IDEA Consultants, Inc., Hayabuchi 2-2-2 Tsuzuki, Yokohama 224-0025,

Kanagawa, Japan

Full list of author information is available at the end of the article
}

that intensive midwinter lighting activity (Dec.-Feb.) in the Hokuriku district tends to be concentrated within an area tens of kilometers from the coastline. In another study, Sugita and Matsui (2012) examined seasonal and inter-annual variations of lightning frequency around Japan based on 10 years of observations gathered by the Japan Lightning Detection Network (JLDN). Also, Ishii et al. (2014) used data from the LIghtning DEtection Network system (LIDEN) to provide a statistical overview of lighting activity tendencies all around Japan.

However, the meteorological conditions that determine the characteristics of the lightning frequency distribution and its seasonal changes have not been discussed in detail in previous studies. For example, although Fujisawa and Kawamura (2005) gave a statistical overview of the meteorological conditions on days in which intensive lightning activity was observed in the Hokuriku district, their main focus was on how the meteorological conditions differed between lightning and non-lightning days. They did not examine the reasons behind the regional and seasonal differences of lightning frequency in detail. Similarly, Tsurushima et al. (2014) examined the averages of meteorological elements for days on which the daily 
lightning frequency exceeded 100 strokes/day during the cold season (Oct.-Mar.) in Tohoku and the eastern part of the Hokuriku district. While the results suggested that cold-season lightning may be primarily caused by synoptic-scale cyclones, variations between individual cases and the relationship between lightning frequency distribution and meteorological disturbances were not thoroughly discussed. Since there are various types of meteorological disturbances (cyclones, fronts, the Japan sea Polar air mass Convergence Zone (JPCZ), upper troughs, etc.) that cause winter lightning in Japan (Kitagawa 1996; Sugita and Matsui 2008), their individual contributions to lightning distribution patterns and their seasonal tendencies are worth investigating.

The aim of this study is to identify major types of winter lightning and to examine the relationships between their lightning frequency distributions and meteorological disturbances based on LLS observational data from the Tohoku district and the eastern part of the Hokuriku district (including Niigata and Toyama Prefectures) (Fig. 1).

In order to identify the major types of winter lightning, hierarchical cluster analysis was applied to lightning frequency distributions of individual cases. We studied some typical cases to clarify the links between lightning frequency distribution and meteorological conditions.

\section{Methods/Experimental}

\section{Observational lightning data}

This study is based on 17 years worth of lightning observations (the 1994-1995 to 2010-2011 winter seasons) obtained by the LLS of Tohoku Electric Power Company. The LLS consists of nine IMPACT sensors distributed in the Tohoku district as shown in Fig. 2. IMPACT sensors are used to detect electromagnetic pulses emitted from lightning discharges and estimate the geo-location of lightning strokes within the Tohoku area, the eastern part of Hokuriku, and the northern part of the Kanto plane. The LLS detects mainly cloud to ground (CG) and ground to cloud (GC) lightning discharges. The detection efficiency of the LLS for wintertime CG/GC strokes is estimated to be $60 \%$, and the lightning location accuracy is approximately $2 \mathrm{~km}$ (Honma et al. 1998; Honma 2012).

In this study, lightning discharges with peak electric currents $\left(I_{p}\right)$ ranging from -10 to $+20 \mathrm{kA}$ were omitted from the analysis. Considering the recommendation of Cummins et al. (1998), lighting with small $I_{p}$ may include cloud discharges that are difficult for the LLS to locate precisely.

Based on the lightning detection range shown in Fig. 2, coastal areas of the Tohoku district and the eastern part of the Hokuriku district including Niigata and Toyama Prefectures (hereinafter referred to as the Hokuriku district) were selected as the study area. Additionally, the LLS in the Tohoku district, originally installed in 1994, was upgraded in 2011, resulting in improved measurement accuracy after 2011 (Honma et al. 2012). Thus, the winter seasons from 1994-1995 to 2010-2011 (17 years) were chosen as the study period in order to avoid discontinuity in data quality.

\section{Meteorological data}

Since this study examines detailed meteorological fields associated with lightning activity, high-resolution gridded meteorological data called the Meso-Scale Model Grid Point Value (MSM-GPV) was adopted for the

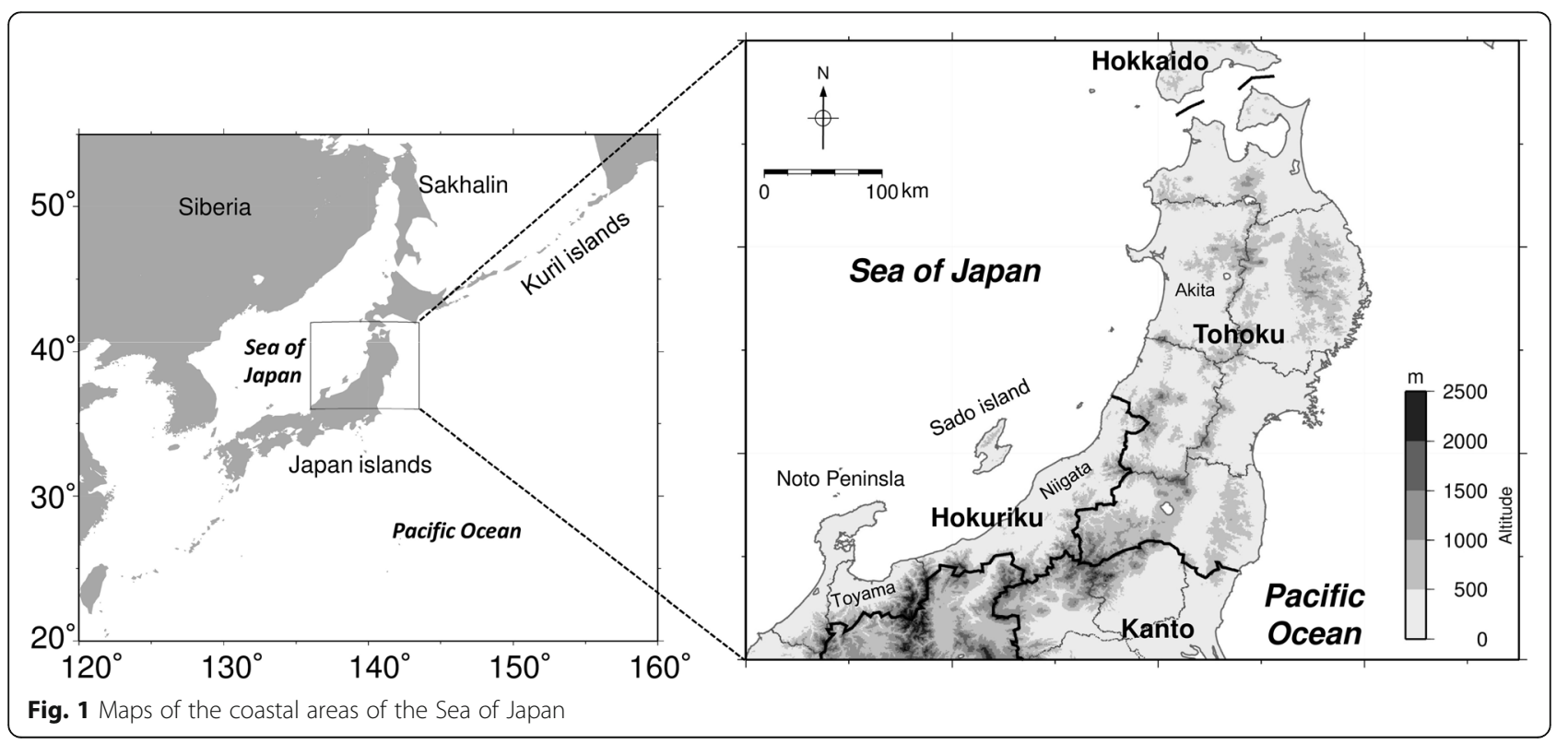




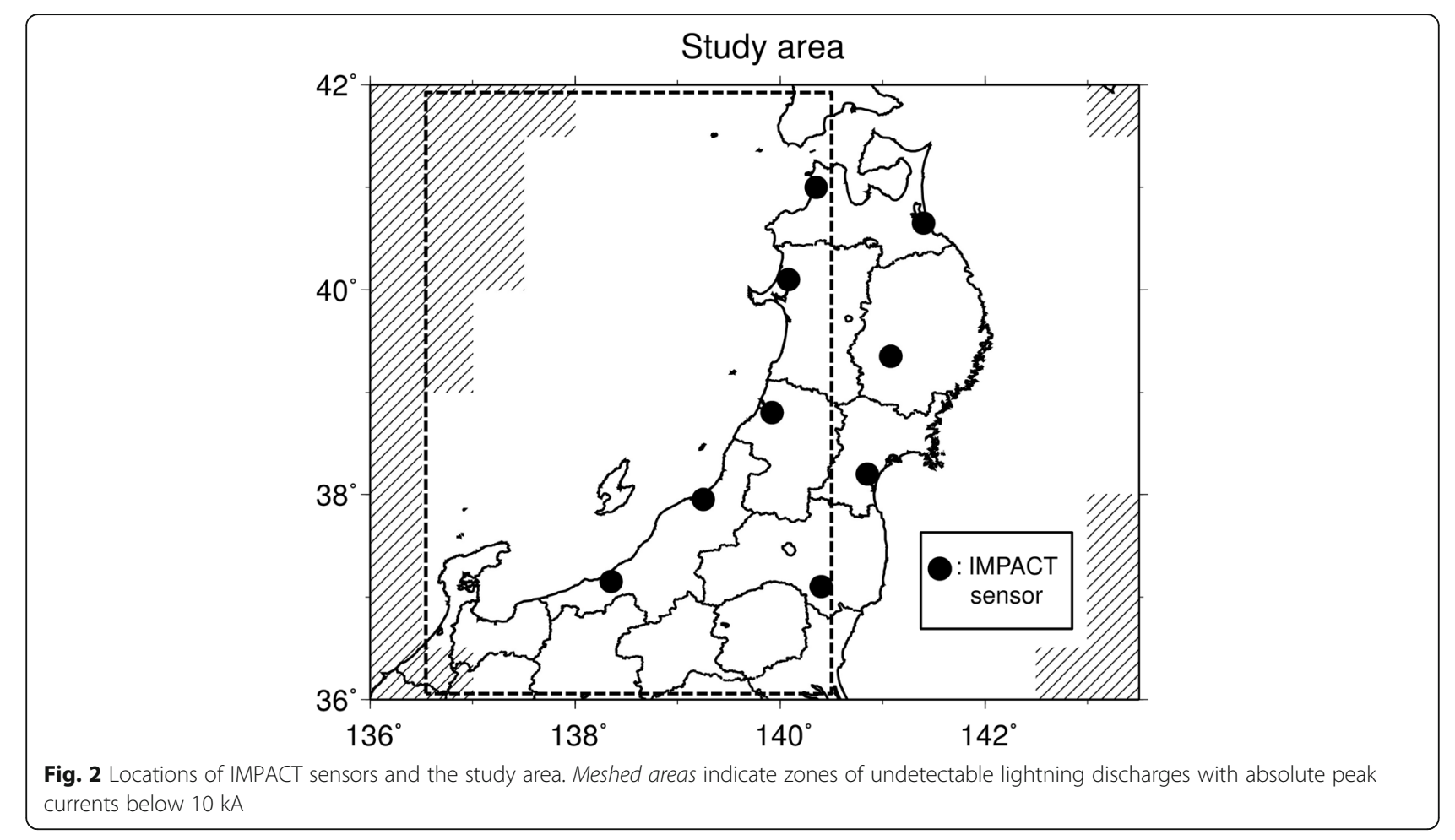

analysis. MSM-GPV data includes objective analysis information calculated by the Meso-Scale Model (MSM) of the Japan Meteorological Agency (JMA). The MSMGPV data has a spatial resolution of $10 \mathrm{~km}$ and a temporal resolution of $3 \mathrm{~h}$.

\section{Selection of cases}

The winter lightning incidents (WL cases) to be used in the cluster analysis and case studies were selected based on time series graphs of lightning frequency, hourly lightning frequency maps, and meteorological radar images. We define a WL case as an episode when lightning activity is spatially and temporally isolated as illustrated in Fig. 3. However, cases with fewer than 100 total strokes were omitted since this study focuses on predominant cases that reflect the statistical features of the lightning frequency distribution. WL cases were selected from those occurring from October to March (the cold season), which is the regular winter lightning activity period in the Tohoku and Hokuriku districts (Tsurushima et al. 2014).

During the entire study period (the cold seasons of 17 consecutive years), 430 incidents were selected as WL cases. The number of WL cases in each month is shown in Table 1.

\section{Cluster analysis}

The cluster analysis for separating the WL cases into distinct types was conducted following the procedures listed below. (a) A lightning frequency map of each WL case was created by counting lightning strokes within $50 \mathrm{~km} \times 50 \mathrm{~km}$ grid cells in the study area so that small-scale (less than $50 \mathrm{~km}$ ) fluctuations in the lightning frequency patterns of the WL cases could be neglected.

(b) The lightning frequency maps created in (a) were approximated by linear summations of empirical orthogonal functions (EOFs) as shown in Eq. (1).

$\mathbf{X}=\sum_{n=1}^{22} \lambda_{n} \mathbf{f}_{n}$

$\mathbf{X}$ indicates the lightning frequency in each grid cell expressed in vector format. $\mathbf{f}_{n}$ and $\lambda_{n}$ denote the $n$th component of the EOF and its corresponding eigenvalue. The EOF summation stops at $n=22$ since this is sufficient to explain $80 \%$ of the variance of the WL cases.

(c) Finally, Ward's clustering was applied to 22 eigenvalues $\left(\lambda_{n}\right)$ of each WL case obtained in the EOF analysis in (b).

\section{Case studies}

In order to clarify the relationship between lightning frequency distribution and meteorological fields, we calculated three meteorological parameters, "surface wind divergence," "convective instability index," and "height at $-10{ }^{\circ} \mathrm{C}$," 

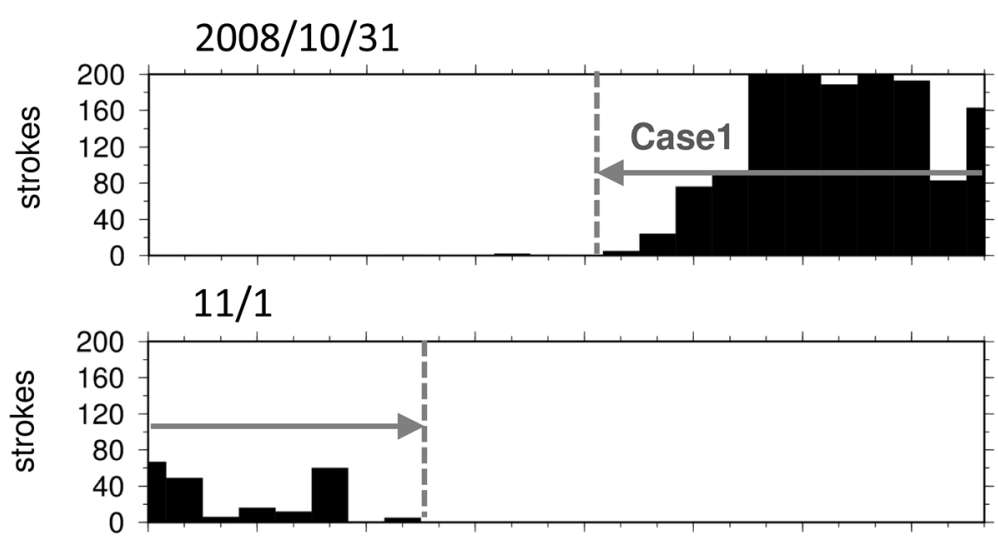

$11 / 2$

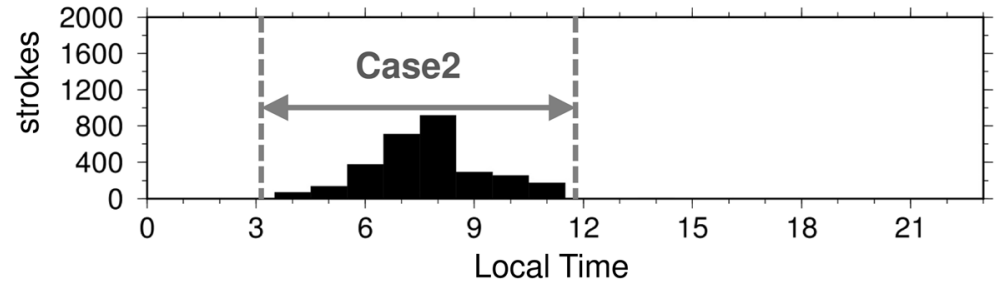

Fig. 3 Example of WL case selection based on time series graphs of lightning frequency

based on the MSM-GPV data and then compared them with lightning frequency distributions of the WL cases.

Surface wind divergence (divU) is defined as

$$
\operatorname{div} U=\frac{\partial u}{\partial x}+\frac{\partial v}{\partial y}
$$

where $u$ and $v$ are the westerly and southerly wind components at the surface. A large negative value of $\operatorname{divU}$ indicates a strong updraft near the surface. Previous studies have shown that $\operatorname{div} U$ corresponds quite well with lightning activity and is helpful in understanding the relationship between lightning occurrences and surface wind fields (Fujisawa and Kawamura 2005; Tsurushima et al. 2014).

The convective instability index $(\triangle \mathrm{EPT})$ is defined as the difference between the equivalent potential temperatures

Table 1 Numbers of WL cases selected by month

\begin{tabular}{ll}
\hline Month & Number of WL cases \\
\hline October & 97 \\
November & 130 \\
December & 99 \\
January & 41 \\
February & 28 \\
March & 35 \\
Total & 430 \\
\hline
\end{tabular}

(EPTs) of the lower and upper layers of the atmosphere. $\triangle \mathrm{EPT}$ is expressed as

$$
\Delta \mathrm{EPT}=\mathrm{EPT}_{\text {srf. }-900 \mathrm{hPa}}-\mathrm{EPT}_{600-400 \mathrm{hPa}}
$$

where $\mathrm{EPT}_{\text {srf.-900 } \mathrm{hPa}}$ is the vertical mean EPT from the surface to $900 \mathrm{hPa}$, while $\mathrm{EPT}_{600-400 \mathrm{hPa}}$ is the vertical mean EPT from 600 to $400 \mathrm{hPa}$. A large $\triangle \mathrm{EPT}$ value indicates intensive thermal convection activity from the surface to a height of approximately $5-8 \mathrm{~km}$ in the atmosphere, which corresponds to the altitude of wintertime thunderclouds (Kitagawa and Michimoto 1994). Thus, $\triangle \mathrm{EPT}$ can be regarded as an indicator of the potentiality of convective cloud formation. Although $\triangle \mathrm{EPT}$ may also be regarded as the strength of resultant convection activity induced by pre-existing thunderclouds, for simplicity's sake, this study adopts the former interpretation.

The values of $\operatorname{div} \mathrm{U}$ and $\triangle \mathrm{EPT}$ indicate the strength of updraft and convection activity, respectively, in relation to the formation and development of convective clouds. However, even when these parameters indicate convective cloud formation, a cloud does not produce lighting discharges unless it is electrified. One simple indicator of the possibility that a cloud is electrified is the height of the $-10{ }^{\circ} \mathrm{C}$ isotherm $\left(\mathrm{H}_{10}\right)$. According to Michimoto (1993), intensive lightning activity occurs mostly when $\mathrm{H}_{10}>1.8 \mathrm{~km}$, while weak or no lightning activity is observed when $\mathrm{H}_{10}<1.8 \mathrm{~km}$. Michimoto (1993) insisted that the dependency of lightning activity on $\mathrm{H}_{10}$ could be related to the strength of the updraft around the $-10{ }^{\circ} \mathrm{C}$ 
level, where the charge separation is most effective (Takahashi 1984). As $\mathrm{H}_{10}$ rises, the maximum updraft velocity around the $-10{ }^{\circ} \mathrm{C}$ level becomes strong enough to cause charge separation, which eventually produces intensive lightning activity.

\section{Results and Discussion}

\section{Average cold-season lightning frequency distributions}

Figure 4 displays average lightning frequency distributions in the Tohoku and Hokuriku districts from October to March, during the cold season. The lightning frequency in each grid cell shows the percentage of lightning strokes counted in that cell relative to the total lightning frequency in the whole study area (the total lightning frequency is shown in the bottom-right corner of each map).

During the late autumn season (Oct.-Nov.), the lightning frequency in the study area is the highest (40,023 strokes) with the most intensive lightning activity recorded in the coastal and open sea areas of the Tohoku district. During midwinter (Dec.-Jan.), lightning frequency drops to 6818 strokes and the region of most intense lightning activity moves southward to the Hokuriku district, where most of the lightning tends to be concentrated near the coastline. Late winter (Feb.-Mar.) displays the lowest lightning frequency (2305 strokes). Its lightning frequency distribution is similar to that in midwinter. However, the late winter season can be distinguished by less lightning activity in Niigata Prefecture and more lightning in Akita Prefecture.

\section{Results of the cluster analysis}

In order to identify the major types of WL cases that explain the statistical features of lightning activity in Fig. 4, cluster analysis was applied to $430 \mathrm{WL}$ cases. As a result, these $\mathrm{WL}$ cases were classified into five clusters $(\mathrm{C} 1, \mathrm{C} 2, \mathrm{C} 3, \mathrm{C} 4, \mathrm{C} 5)$ as shown in Fig. 5. Among the five clusters, it is clear that $\mathrm{C} 1(N=156)$ and $\mathrm{C} 4(N=144)$ are predominant, containing $70 \%$ of all the WL cases.

Figure 5 shows that $\mathrm{C} 1$ is characterized by high lightning frequency over the coastal and open sea areas of the Tohoku district. This is similar to the average lightning frequency distribution in late autumn (Fig. 4). The lightning frequency distribution of $\mathrm{C}$, on the other hand, is similar to the midwinter pattern, being characterized by high lightning frequency in the coastal areas of the Hokuriku district.

Figure 6 shows the monthly occurrence frequency of the five clusters. As indicated in Fig. 6, most of the WL cases in late autumn belong to $\mathrm{C} 1$, while midwinter is relatively dominated by $\mathrm{C} 4$. Thus, $\mathrm{C} 1$ and $\mathrm{C} 4$ are the predominant types of WL cases in late autumn and midwinter, respectively.

\section{Meteorological conditions for winter lightning occurrence} We examined synoptic-scale atmospheric conditions for $\mathrm{C} 1$ and $\mathrm{C} 4$ cases (300 in total) on the basis of daily surface weather charts provided by the JMA. The weather charts in Fig. 7 display some typical examples of WL cases. Approximately $79 \%$ of $\mathrm{C} 1$ and $\mathrm{C} 4$ incidents (238 cases) were caused by synoptic-scale or meso-scale cyclones passing in the vicinity of the Japanese islands (Fig. 7a-e). Although these cyclones vary from case to case, they were roughly categorized based on their tracks and geometric shapes.

Firstly, we focused on cyclones with a single center (Fig. $7 \mathrm{a}-\mathrm{c}$ ) and divided them into three categories: SK, SJ, and PO cyclones. The definitions of each category are shown in Fig. 8. Cyclones passing near Sakhalin and the Kuril Islands (northward from the $44^{\circ} \mathrm{N}$ line) as shown in Fig. 7a are classified as SK cyclones. Cyclones shown in Fig. 7b, c are classified as SJ cyclones or PO cyclones based on whether their centers tended to pass

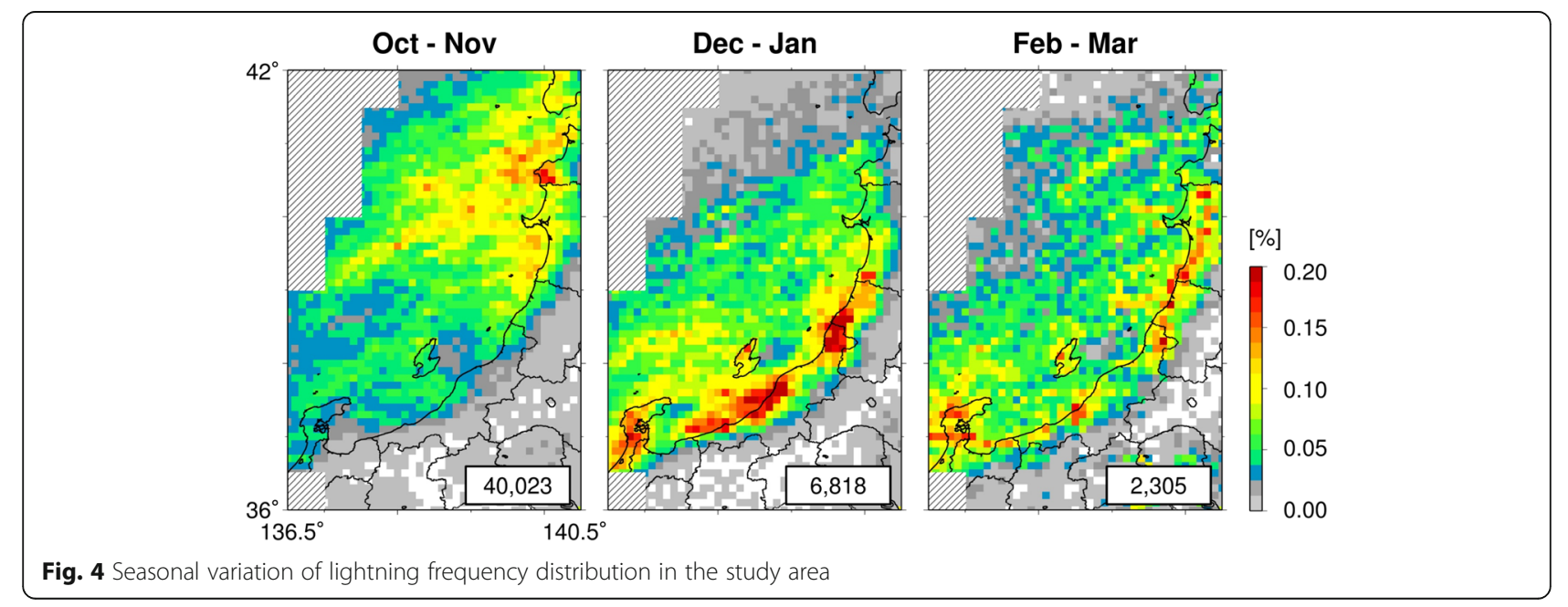




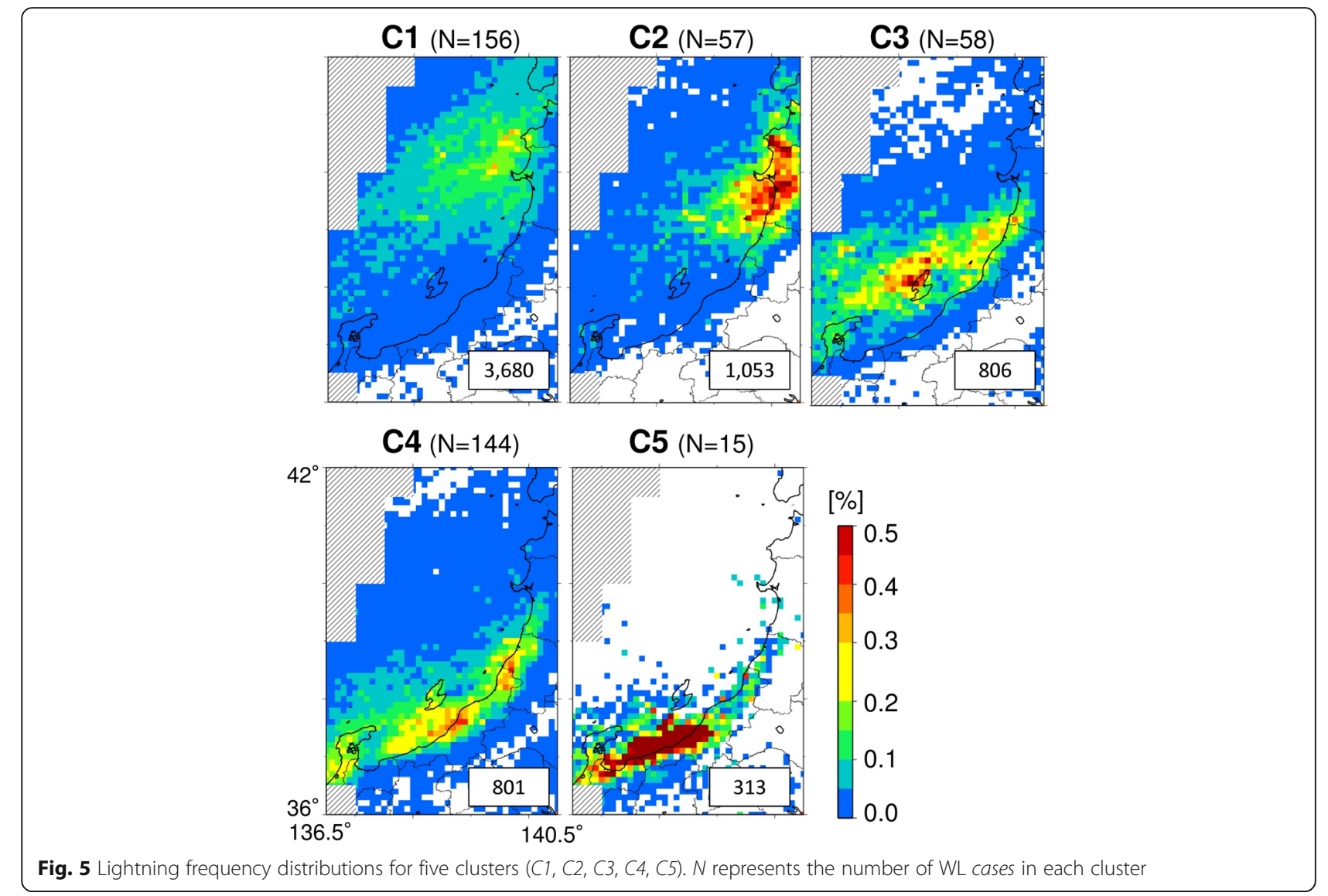

over the Sea of Japan or the Pacific Ocean. It should be noted that there are some cases where SK and SJ cyclones appear simultaneously. We categorized these as SJ cyclones because SJ cyclones pass closer to the study area and may have a greater impact on lightning frequency distribution than SK cyclones.
Secondly, cyclones with multiple centers are labeled as "MC" in Fig. 7d, e. An MC cyclone typically has two centers, one located north of Japan and the other over the Pacific Ocean. MC cyclones were subdivided into two categories: $\mathrm{MCI}$ and MCII. When the centers of an MC cyclone pass simultaneously over the SK and PO

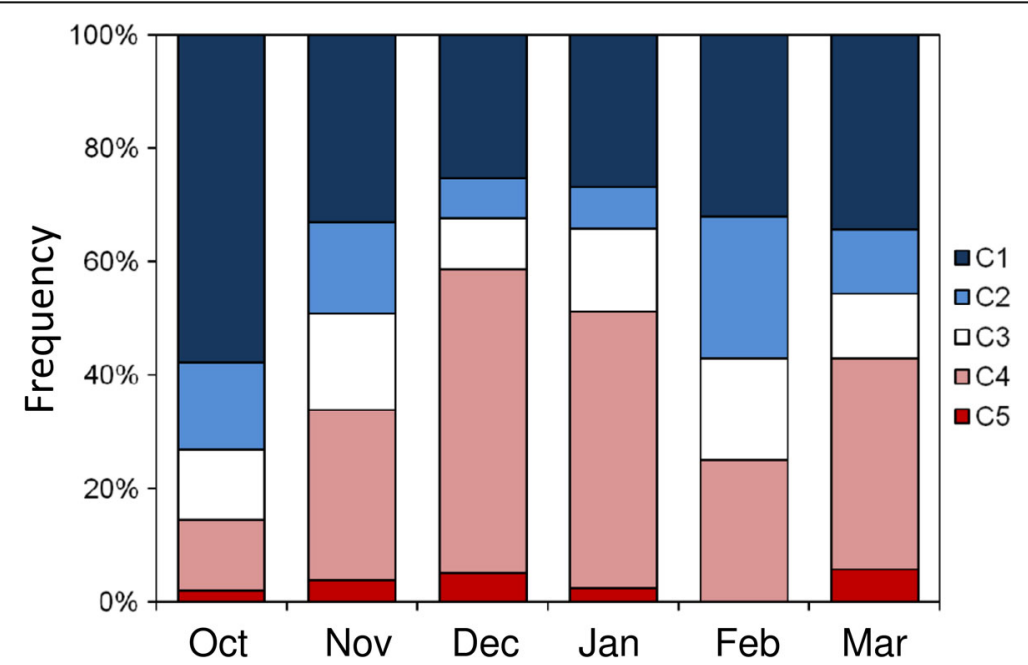

Fig. 6 Seasonal variation of lightning occurrence for five clusters $(C 1, C 2, C 3, C 4, C 5)$ 


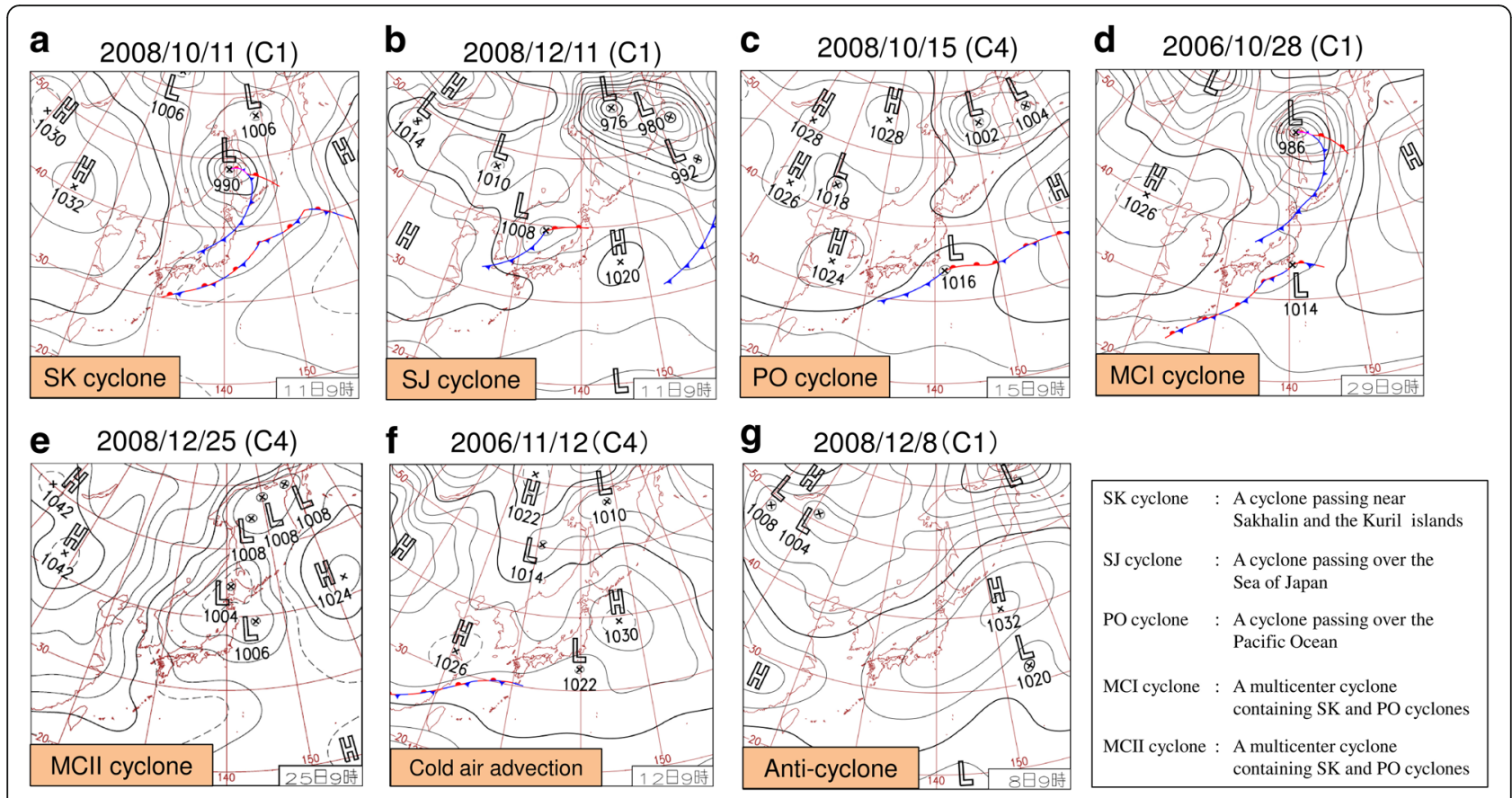

Fig. 7 a-g Examples of surface weather charts corresponding to $\mathrm{Cl}$ and $\mathrm{C} 4$

cyclone areas indicated in Fig. 8, the cyclone is classified as MCI (Fig. 7d). Similarly, when the cyclone centers pass over the SJ and PO areas simultaneously, the cyclone is classified as MCII (Fig. 7e).

Thirdly, Fig. 7f, g depicts two cases that are not directly associated with cyclone activity. Approximately $13 \%$ of the $\mathrm{C} 1$ and $\mathrm{C} 4$ cases (38 cases) occurred when neither cyclones nor fronts were passing the vicinity of the study area during the entire period of the WL case. For example, Fig. $7 \mathrm{f}$ shows a typical case of "cold air

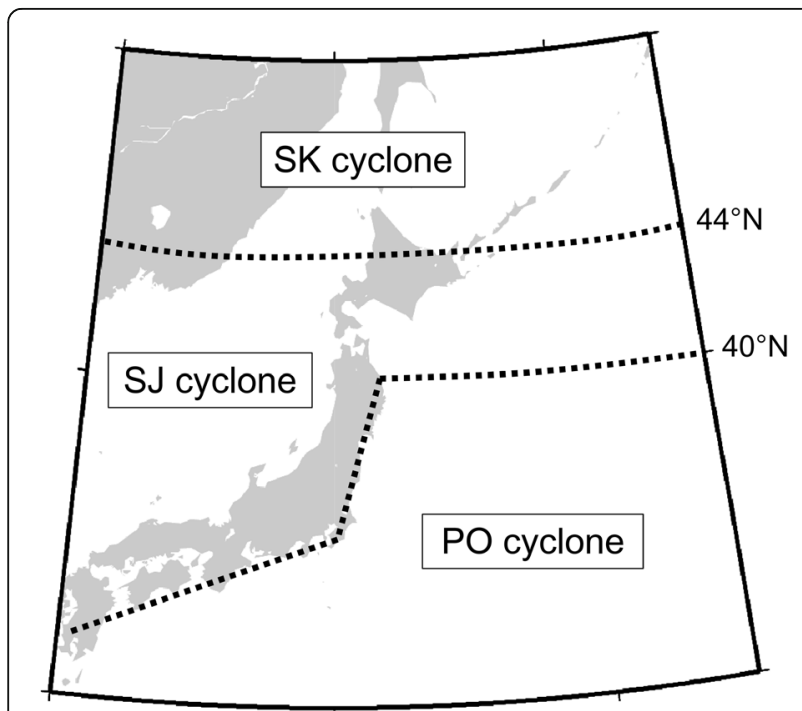

Fig. 8 Definitions of SK, SJ, and PO cyclones advection" when a northerly or northwesterly wind from the Siberian continent is dominant in the study area throughout the entire period of lighting activity. The difference between cold air advection cases and cyclone cases is described in Fig. 9. In the cold air advection cases, the wind direction observed at Sakata (a JMA weather station) is always northwesterly during the lightning activity. In contrast, the wind direction for MCII cyclone cases changes drastically from southeasterly to northwesterly indicating the passing of the cyclone. In addition to daily weather charts, we also examined hourly surface wind directions to distinguish cold air advection cases from cyclone cases. Also, Fig. $7 \mathrm{~g}$ shows a case in which the study area is at the edge of an anti-cyclone centered over the Pacific Ocean. This is an example of an "anti-cyclone" case, a rarity among the WL cases.

The remaining 24 (8\%) of the $\mathrm{C} 1$ and $\mathrm{C} 4$ cases cannot be classified into the categories outlined above. These are labeled as "Other" and contain overlaps of several categories. For example, when an SJ cyclone turns into an MCII cyclone while a WL case is occurring, the case would be classified as "Other."

The atmospheric conditions for the $\mathrm{C} 1$ and $\mathrm{C} 4$ cases are summarized in Table 2. Table 2 indicates that $\mathrm{C} 1$ cases are most frequently observed during the late autumn season and are associated with SK or SJ cyclones, which are likely to take relatively northern courses than $\mathrm{PO}$ or MC cyclones. Contrarily, C4 cases seem to be most frequent during the midwinter season and are associated 


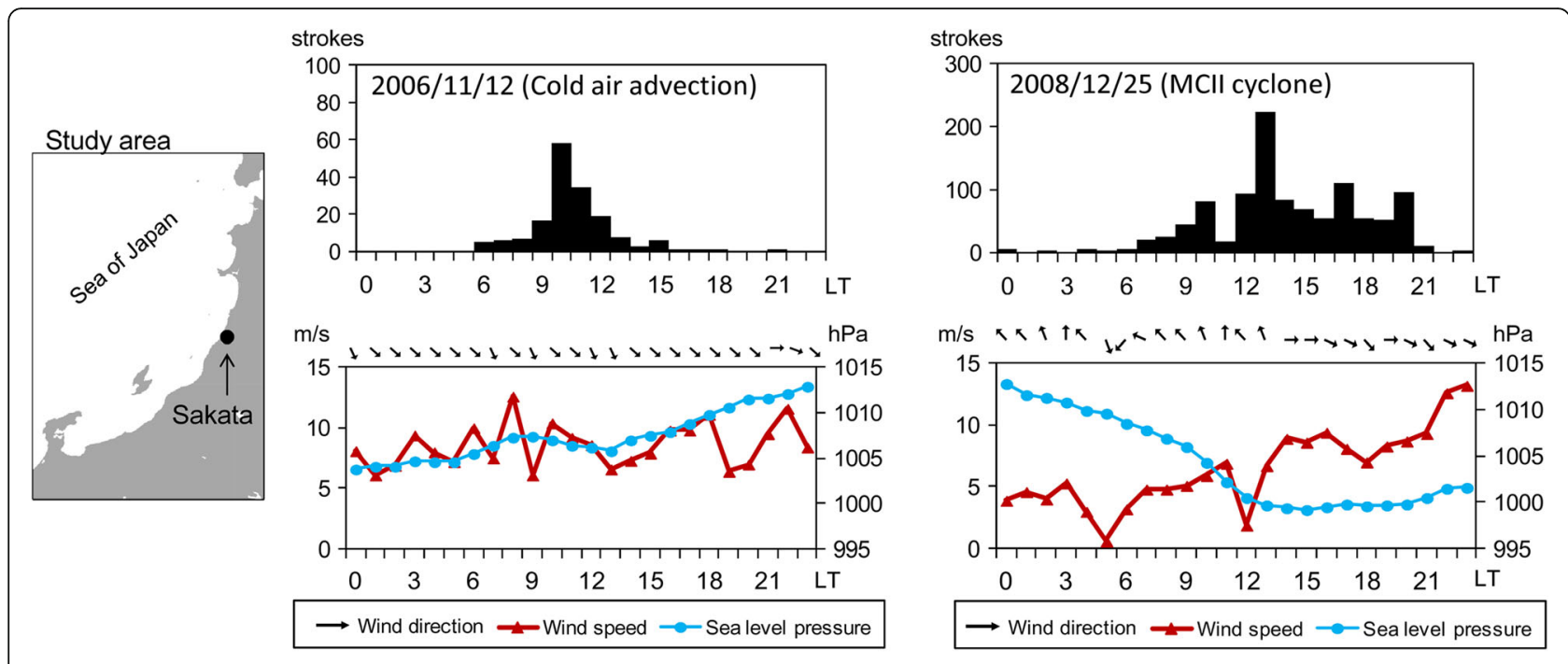

Fig. 9 Comparison of surface winds and sea-level pressure. Observations at Sakata (a JMA weather station) for cold air advection cases and MCII cyclone cases

with MCII cyclones, which pass further to the south than SK or SJ cyclones. Additionally, Table 2 shows that C4 cases are sometimes caused by cold air advection that is not directly associated with cyclone activity.

\section{WL case types}

In summary, three major types of WL occurrences were identified as illustrated in Table 3. Type A incidents are C1 cases frequently observed during late autumn, associated with SK or SJ cyclones. Type B cases are C4 occurrences that happen mainly in midwinter, associated with MCII cyclones. Type $\mathrm{C}$ cases, which are less frequent than type $\mathrm{A}$ or type $\mathrm{B}$, are $\mathrm{C} 4$ cases associated with cold air advection. According to Kitagawa (1996), type $C$ is regarded as "Advection lightning," a typical kind of winter lightning.

\section{Type A case study}

As a typical type A occurrence, we chose a WL case observed from 10 October to 11 October 2008 (case A).

Table 2 Numbers of cases in categories C1 and C4 grouped by month and atmospheric conditions. Cell color shows relative frequency (\%)

\begin{tabular}{|c|c|c|c|c|c|c|c|c|c|}
\hline \multicolumn{9}{|l|}{$\mathrm{C} 1$} & \multirow[b]{5}{*}{$(\%)$} \\
\hline Type & \multirow{2}{*}{ SK } & \multirow{2}{*}{ SJ } & \multicolumn{2}{|c|}{ MC } & \multirow{2}{*}{$\mathrm{PO}$} & \multirow{2}{*}{$\begin{array}{c}\text { Cold air } \\
\text { advection }\end{array}$} & \multirow{2}{*}{$\begin{array}{c}\text { Anti } \\
\text {-cyclone } \\
\end{array}$} & \multirow{2}{*}{ Other } & \\
\hline Month & & & $\mathrm{MCI}$ & MCII & & & & & \\
\hline Oct. & 18 & 16 & 11 & 6 & 0 & 1 & 1 & 3 & \\
\hline Nov. & 15 & 8 & 5 & 6 & 0 & 1 & 3 & 4 & \\
\hline Dec. & 7 & 8 & 1 & 8 & 0 & 0 & 2 & 0 & $10-$ \\
\hline Jan. & 2 & 3 & 1 & 5 & 0 & 0 & 0 & 0 & $5-10$ \\
\hline Feb. & 2 & 2 & 1 & 3 & 0 & 0 & 0 & 0 & $2-5$ \\
\hline Mar. & 5 & 4 & 1 & 2 & 0 & 0 & 0 & 0 & $0-2$ \\
\hline
\end{tabular}

\begin{tabular}{|c|c|c|c|c|c|c|c|c|c|}
\hline \multirow{2}{*}{ Month } & \multirow[b]{2}{*}{ SK } & \multirow[b]{2}{*}{ SJ } & \multicolumn{2}{|c|}{$M C$} & \multirow[b]{2}{*}{$\mathrm{PO}$} & \multirow{2}{*}{$\begin{array}{c}\begin{array}{c}\text { Cold air } \\
\text { advection }\end{array} \\
\end{array}$} & \multirow{2}{*}{$\begin{array}{c}\text { Anti } \\
\text {-cyclone }\end{array}$} & \multirow[b]{2}{*}{ Other } & \\
\hline & & & MCI & MCI & & & & & \\
\hline Oct. & 2 & 1 & 2 & 2 & 1 & 3 & 0 & 1 & \\
\hline Nov. & 3 & 6 & 5 & 7 & 0 & 14 & 2 & 2 & $(\%)$ \\
\hline Dec. & 2 & 14 & 3 & 21 & 1 & 7 & 1 & 4 & $10-$ \\
\hline Jan. & 2 & 5 & 0 & 6 & 0 & 2 & 0 & 5 & $5-10$ \\
\hline Feb. & 0 & 5 & 1 & 1 & 0 & 0 & 0 & 0 & $2-5$ \\
\hline Mar. & 0 & 4 & 1 & 2 & 1 & 1 & 0 & 4 & 0-2 \\
\hline
\end{tabular}


Table 3 Major WL types

\begin{tabular}{lllll}
\hline Type & Season & $\begin{array}{l}\text { Lighting frequency } \\
\text { distribution }\end{array}$ & Surface weather & $\begin{array}{l}\text { Number of } \\
\text { cases }\end{array}$ \\
\hline A & Oct.-Dec. & C1 & SK or SJ cyclone & 57 \\
B & Nov.-Jan. & C4 & MCll cyclone & 34 \\
C & Nov.-Dec. & C4 & Cold air advection & 21 \\
\hline
\end{tabular}

Time series maps of lightning frequency distribution and synoptic-scale atmospheric conditions for case A are shown in Fig. 10. The locations of cold/warm fronts in Fig. 10b were obtained from JMA's surface weather charts. The lightning frequency distributions for case A indicate that lightning activity commenced over the northwestern part of the Sea of Japan and moved eastward to the coastal areas of the Tohoku district. Figure 10b shows that a cold front associated with an SK cyclone passed over the Sea of Japan on 10 October to 11 October.
In order to clarify the relationship between case A's lightning frequency distributions and meteorological fields, we calculated divU and $\triangle \mathrm{EPT}$ using Eqs. (2) and (3). Figure 11a shows time series maps of surface winds and $\operatorname{div} U$ distributions, while Fig. 11b shows composite maps of $\triangle \mathrm{EPT}$ distributions and wind convergence lines detected in Fig. 11a. In Fig. 11b, strong wind convergence lines (divU $\leq-20\left[\times 10^{-5} / \mathrm{s}\right]$ ) are expressed by solid lines, while weak convergence lines $\left(-20\left[\times 10^{-5} / \mathrm{s}\right]<\right.$ $\left.\operatorname{div} \mathrm{U} \leq-10\left[\times 10^{-5} / \mathrm{s}\right]\right)$ are expressed by dashed lines. Lastly, Fig. 11c shows composite maps of lightning frequency distributions, wind convergence lines, and regions where $\triangle \mathrm{EPT}$ exceeds $10 \mathrm{~K}$ (highlighted in pink).

On 10 October $21 \mathrm{LT}$, a strong wind convergence line was formed as a result of westerly and southerly winds blowing over the Sea of Japan in the northwestern part of the study area. Additionally, the gradient of $\triangle \mathrm{EPT}$ across the convergence line was significantly large, indicating that a boundary existed between the stable air

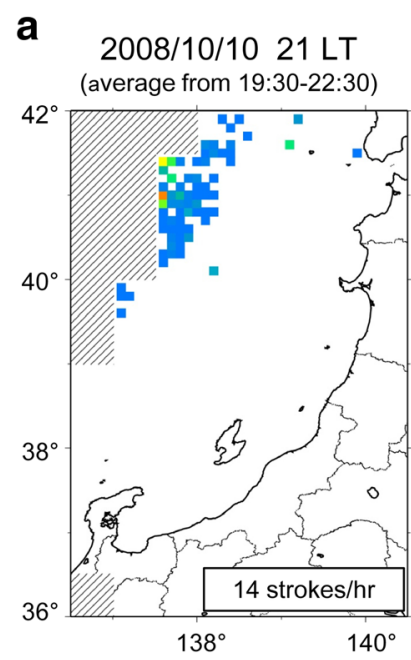

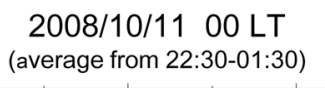

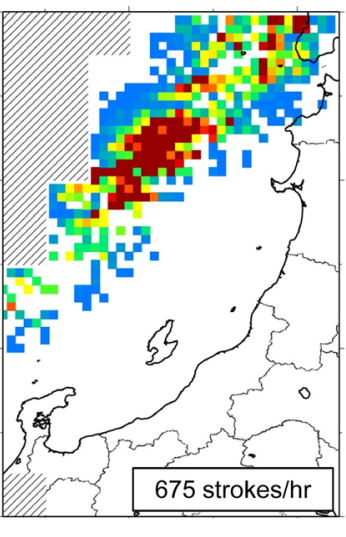

$40^{\circ}$
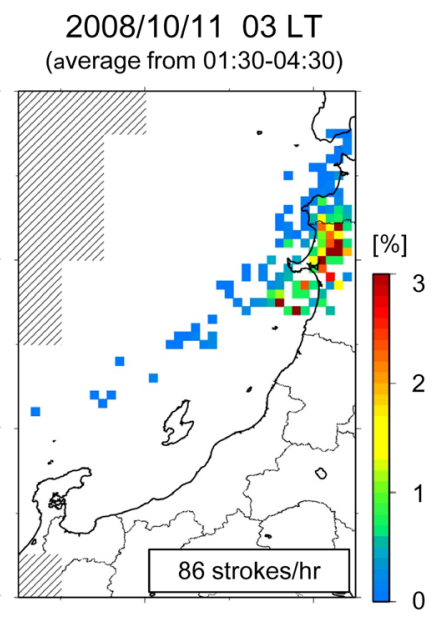

2008/10/11 09 LT surface

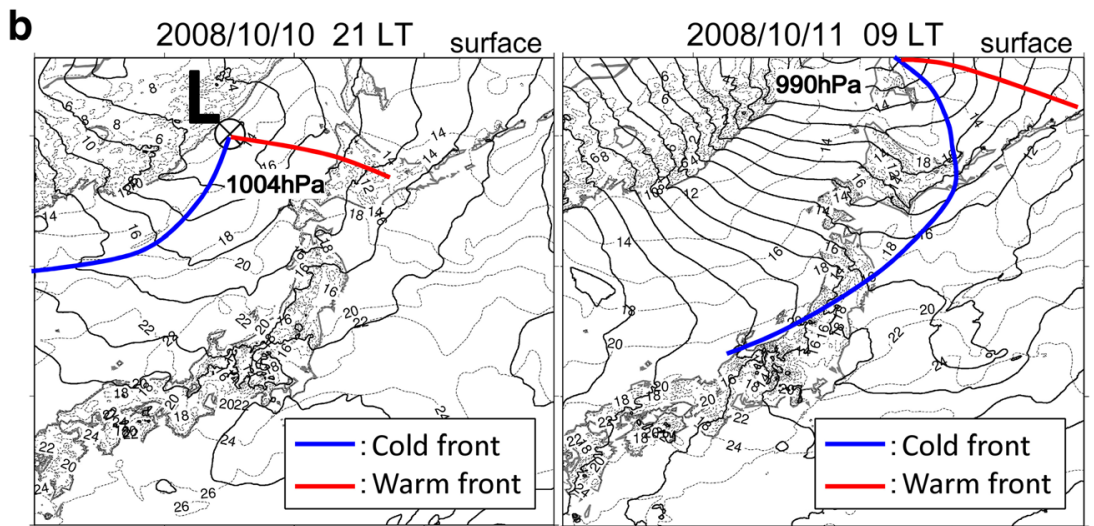

Fig. 10 Lightning frequency distributions and atmospheric conditions at the surface for case A. a Time series maps of lightning frequency distribution. The lightning frequency on the map is an hourly average calculated in a $3 \mathrm{~h}$ time window around the reference time. $\mathbf{b}$ Sea-level pressure (solid lines) and surface air temperature (broken lines) distributions obtained by MSM-GPV. Contour interval of sea-level pressure is $4 \mathrm{hPa}$. "L" represents the center of the cyclone defined as the point at which sea-level pressure is the lowest. Locations of cold/warm fronts are obtained from JMA's surface weather charts 


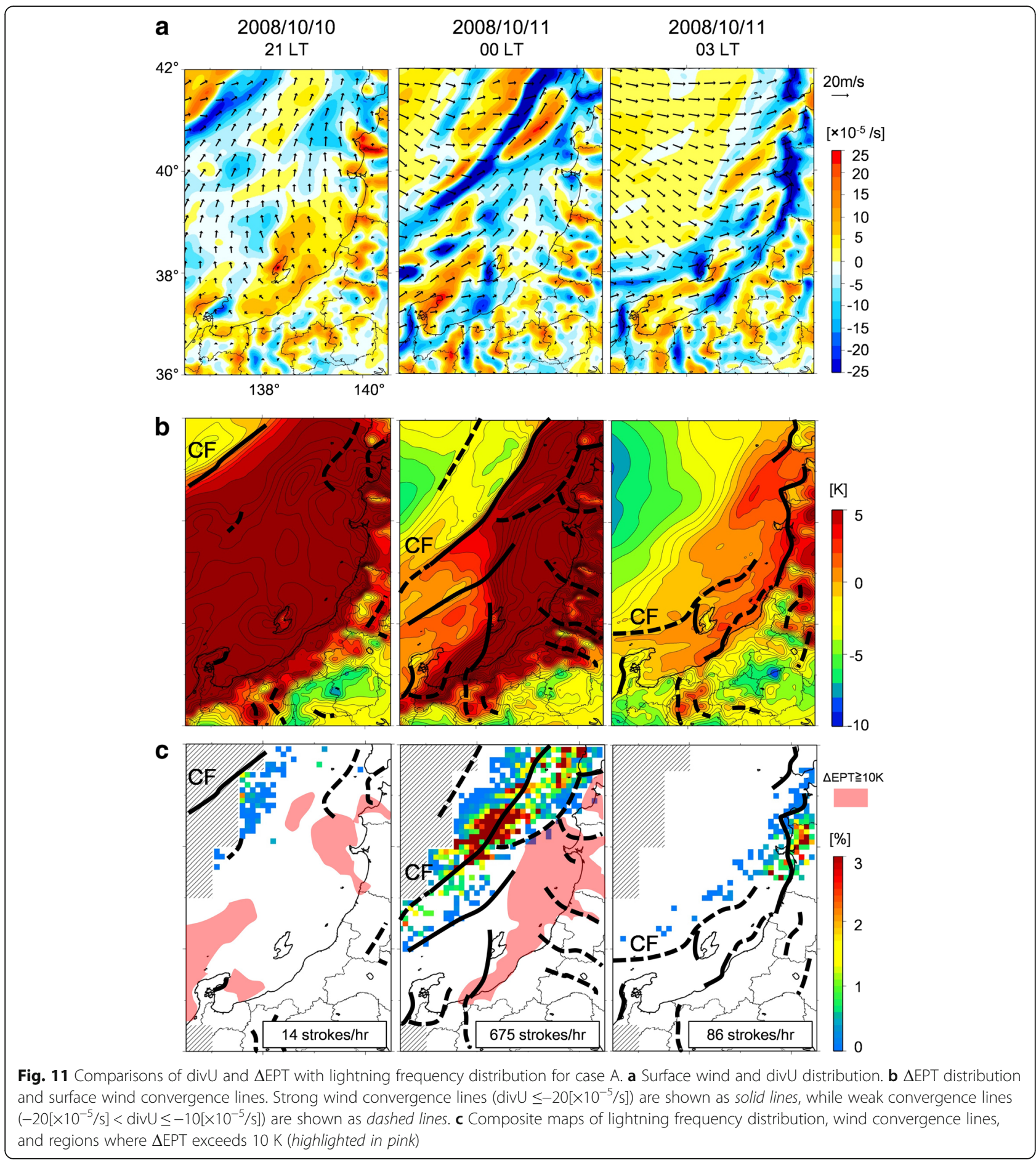

mass and the unstable air mass. These characteristics indicate that the convergence line in the northwestern part of the study area overlapped with the cold front accompanying the SK cyclone (labeled as cold front (CF) in Fig. 11). According to Fig. 11c, lightning strokes were distributed along the convergence line at the cold front.

On 11 October $0 \mathrm{LT}$, the region of high lightning frequency moved eastward as the cold front moved to the offshore areas of the Tohoku district. Furthermore, 11 October 0 LT exhibited the highest lightning frequency (675 strokes/h) during the entire period.

On 11 October $3 \mathrm{LT}$, the wind convergence along the cold front appears to have weakened in the north of the Hokuriku district. Additionally, the $\triangle \mathrm{EPT}$ gradient across the cold front was smaller than during the previous period, also indicating weakening of the cold front. Instead, strong 

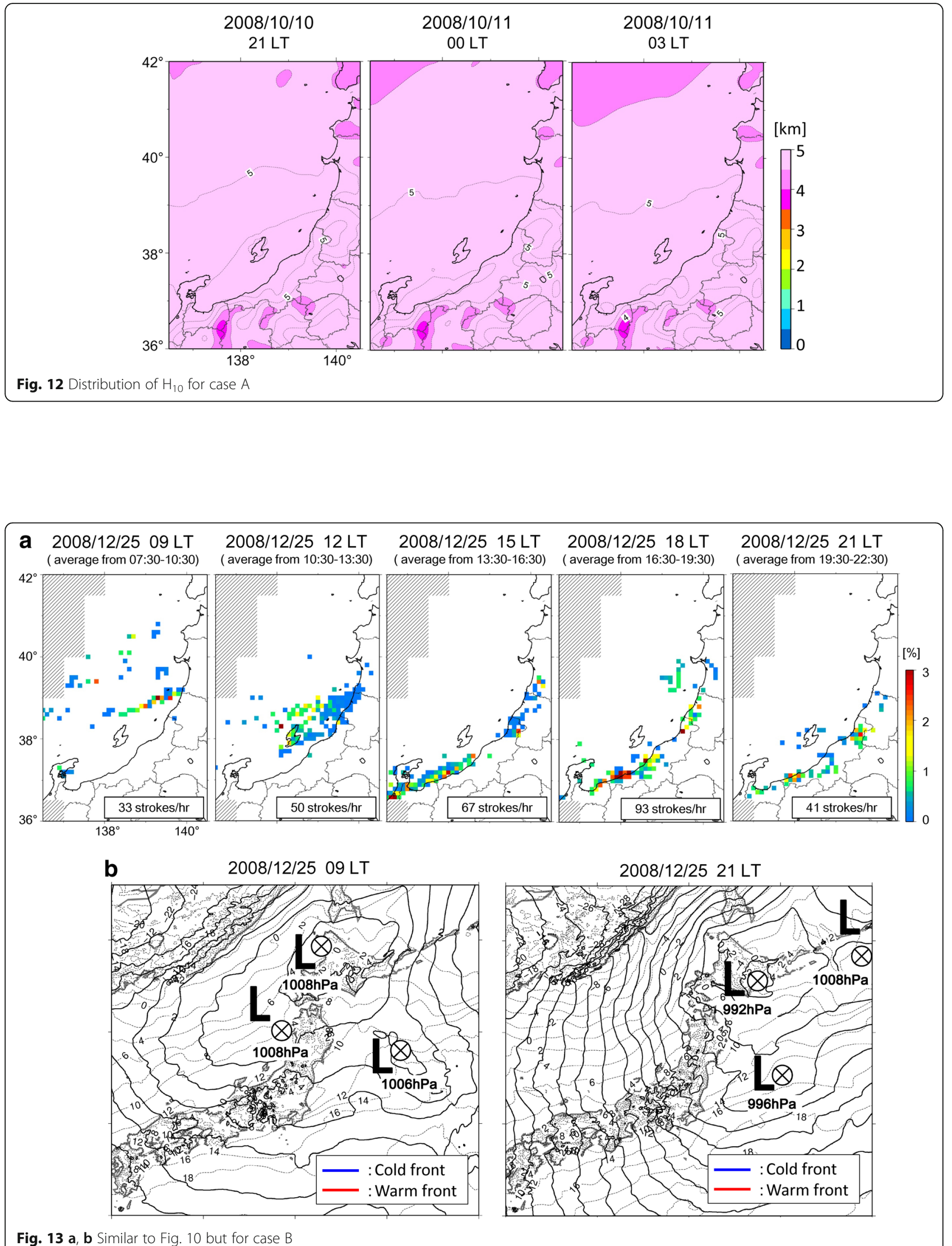
convergence lines, the result of westerly winds decelerating due to topographic effects, appeared in the coastal areas of the Tohoku district. Figure 11c shows that lightning strokes were mainly concentrated in the topographic convergence lines in Tohoku's coastal areas, rather than in the weaker convergence line along the cold front. One mechanism that could explain why this kind of topographic convergence forms is the contrast in surface roughness between land and sea. The higher friction over land causes the wind speed to decelerate and form convergence zones along the coastline. An alternative theory suggested by Ohigashi and Tsuboki (2005) focuses on the possible contribution of land breezes to the development of snow clouds in the Hokuriku district. Thus, in addition to surface roughness, thermally induced local winds such as land breezes, which are caused by temperature gradients between land and sea, may play a significant role in forming wind convergences near the coastline.

Moreover, Fig. 12 shows time series maps of $\mathrm{H}_{10}$. In case $\mathrm{A}, \mathrm{H}_{10}$ exceeds $1.8 \mathrm{~km}$ across the whole study area, sufficient for electrifying thunderclouds and thus for producing intense lightning activity.

\section{Type B case study}

As a typical type B WL case, we chose 25 December 2008 (case B). Time series maps of lightning frequency distribution and synoptic-scale atmospheric conditions for case B are shown in Fig. 13. Case B's lightning frequency distribution indicates that lightning activity commenced over the Sea of Japan and moved southward to

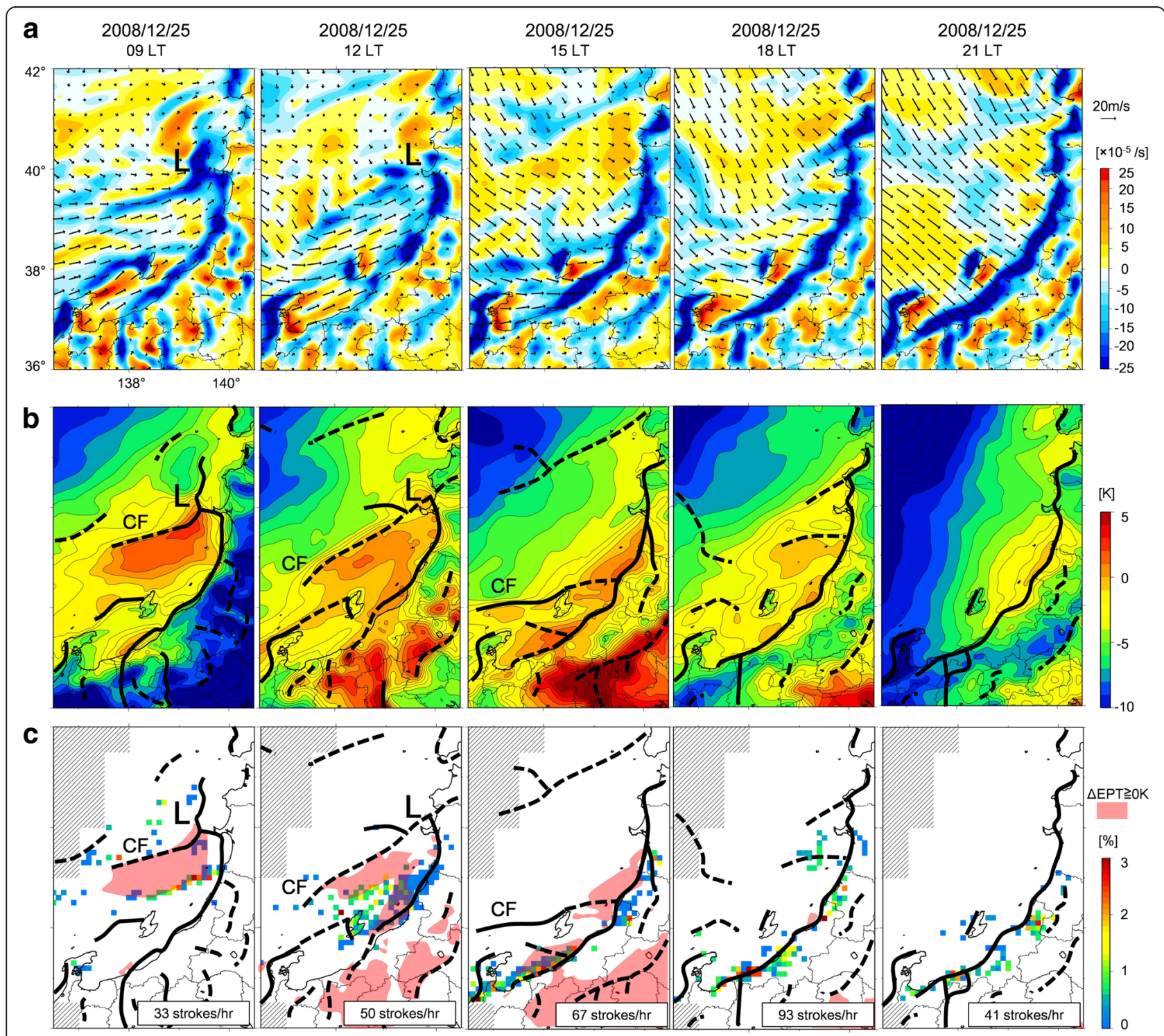

Fig. 14 a-c Similar to Fig. 11 but for case B. "L" represents the center of the cyclone 
the coastal areas of the Hokuriku district. Figure 13b indicates that an MCII cyclone passed over the Japanese islands on 25 December.

Figure 14 compares $\operatorname{div} \mathrm{U}$ and $\triangle \mathrm{EPT}$ and case B's lightning frequency distribution. From 9 LT to $12 \mathrm{LT}$ on 25 December, a weak wind convergence line (labeled CF) was formed by northwesterly and southwesterly winds blowing over the Sea of Japan in the central part of the study area. Based on surface wind and $\triangle \mathrm{EPT}$ distributions in Fig. 14a, b, this weak convergence line can be regarded as a CF, although it is not shown on the surface weather charts (Fig. 13b). In addition, a strong convergence line was formed along the Tohoku coastline in connection with the topographic effects described above in the type A case study. Figure 14c shows that lightning strokes were concentrated over the unstable air mass $(\triangle \mathrm{EPT} \geq 0 \mathrm{~K})$ and along the topographic convergence line in the coastal areas of the Tohoku district rather than over the weak convergence line along the cold front.

On 25 December $15 \mathrm{LT}$, as the cold front moved southward to the offshore areas of the Hokuriku district, the unstable air mass seems to have drawn nearer to the Tohoku and Hokuriku coastline. According to Fig. 14c, regions of high lightning frequency formed over the unstable air mass and topographic convergence lines in the coastal areas, whereas the lightning frequency over the cold front was relatively low. It is also noteworthy that a wind divergence zone formed on the leeward side of Sado Island, possibly influenced by a downdraft from the island's mountains. This may also have factored into the lightning frequency being relatively low on the southeastern side of Sado Island.

From $18 \mathrm{LT}$ to $21 \mathrm{LT}$ on 25 December, the cold front disappeared and the study area was dominated by northwesterly winds blowing over the Sea of Japan. Additionally, topographic convergence lines formed along the Tohoku and Hokuriku coastline, while $\triangle \mathrm{EPT}$ was smaller than in previous periods. Lightning frequency in the area remained high (41-93 strokes/h) with the lightning strokes being concentrated over the topographic convergence lines.

Figure 15 compares $\mathrm{H}_{10}$ and corresponding lightning frequency distributions for case $B$. It shows that $\mathrm{H}_{10}$ exceeded $1.8 \mathrm{~km}$ in the whole study area when the lightning activity began (09-12 LT on 25 Dec.). However, from $18 \mathrm{LT}$ to $21 \mathrm{LT}$ on December 25, when the study area was dominated by northwesterly winds (see Fig. 14a), the region of high $\mathrm{H}_{10}$ was confined to the coastal areas of the Hokuriku district. Since lightning mainly occurs where $\mathrm{H}_{10}>1.8 \mathrm{~km}$, this indicates that from $18 \mathrm{LT}$ to $21 \mathrm{LT}$, the coastal areas of the Hokuriku district were more favorable for cloud electrification than were other regions.

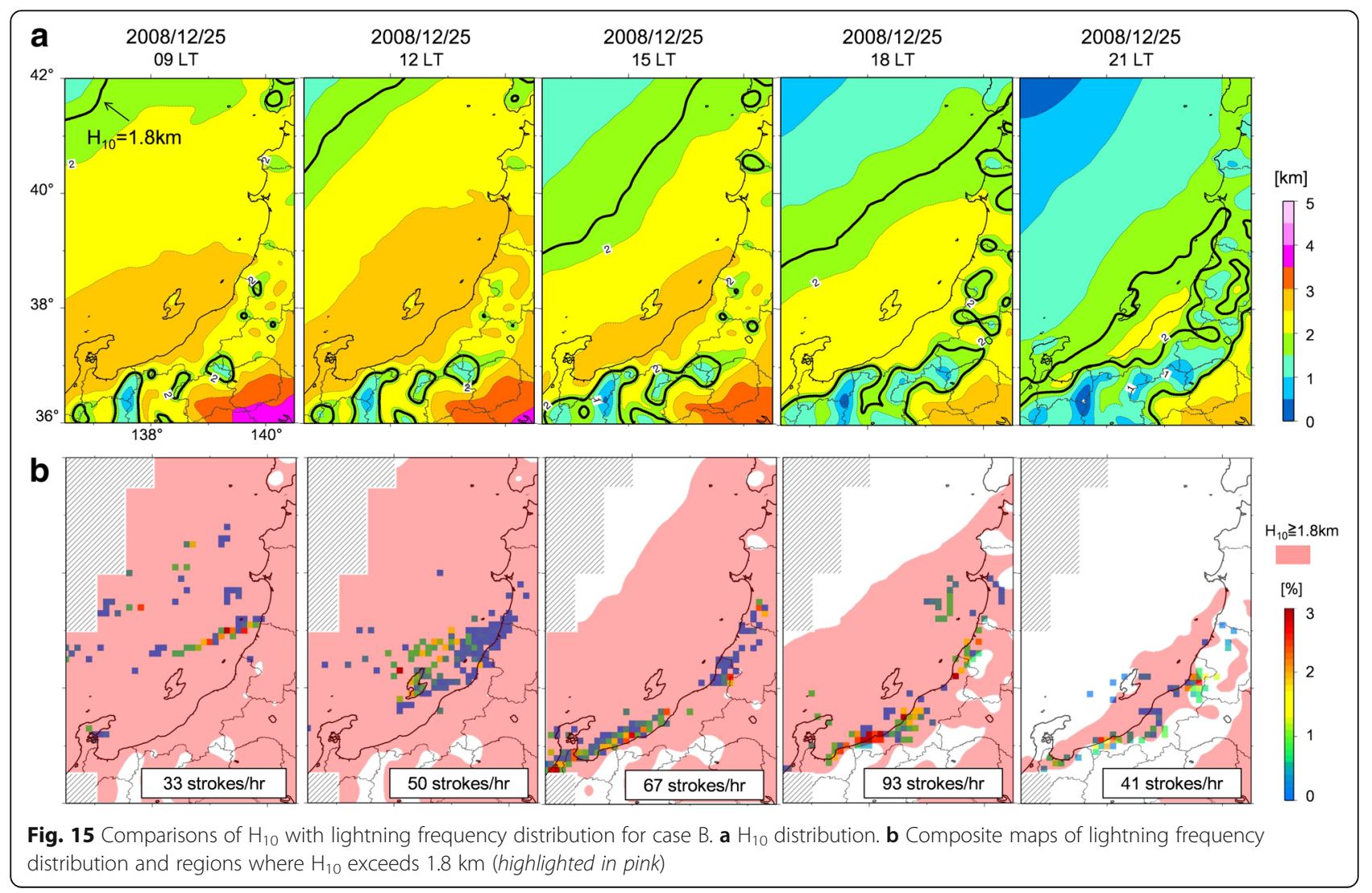



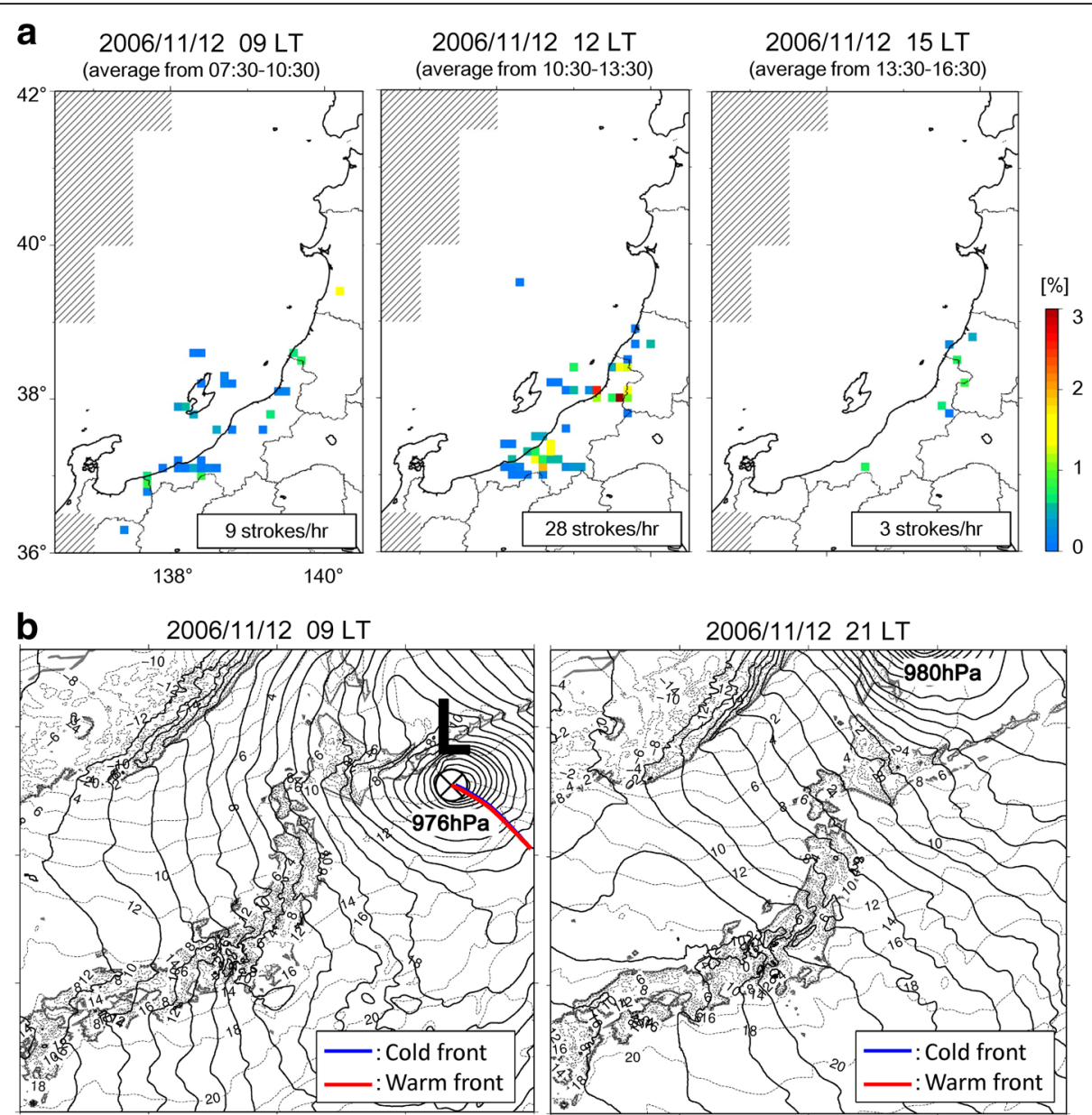

Fig. 16 a, b Similar to Fig. 10 but for case $C$

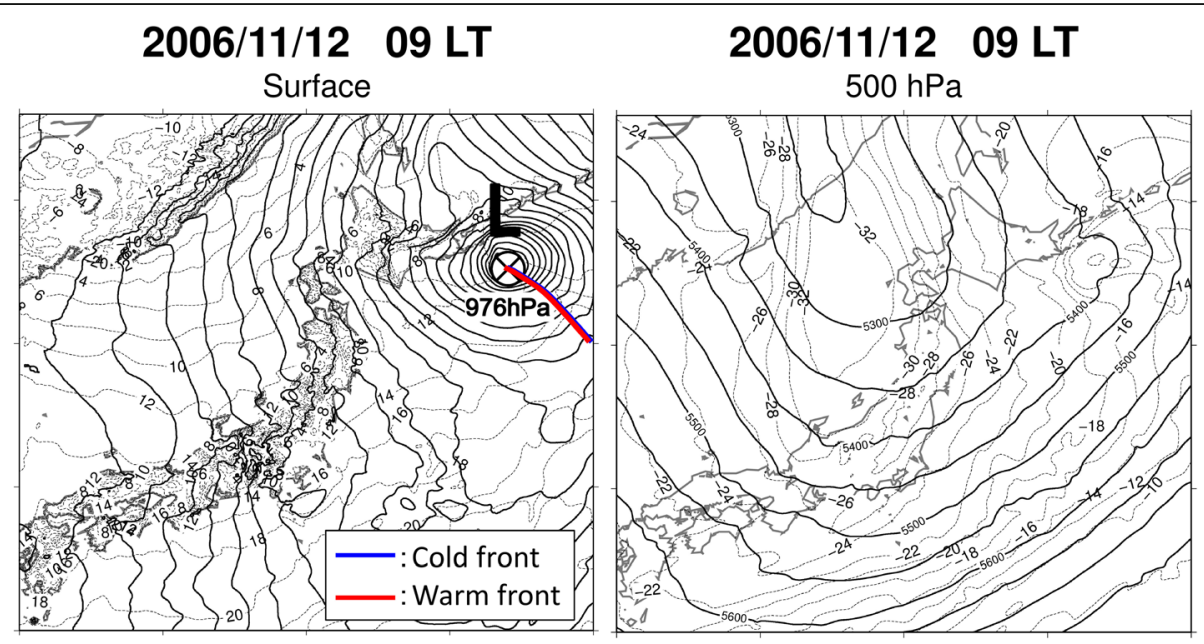

Fig. 17 Atmospheric conditions on 11 November 9 LT, 2006. Sea-level pressure (hPa) (geopotential height (m) at the 500 hPa pressure level) and air temperature distribution $\left({ }^{\circ} \mathrm{C}\right)$ 


\section{Type $C$ case study}

As a representative type $\mathrm{C}$ event, we chose a WL case observed on 12 November 2006 (case C). Time series maps of lightning frequency distribution and synoptic-scale atmospheric conditions for case $\mathrm{C}$ are shown in Fig. 16. The lightning frequency distributions of case $\mathrm{C}$ suggest that lightning activity was mainly concentrated around the coastal areas of the Hokuriku district during the entire period. Figure 16b indicates that the study area was dominated by cold air advection from the Siberian continent.
Although no meteorological disturbance such as a cold front or a cyclone is shown in Fig. 16b, figures for the geopotential height distribution at the $500 \mathrm{hPa}$ pressure level point to the existence of a strong pressure trough as illustrated in Fig. 17.

Therefore, the lightning activity in case $\mathrm{C}$ could possibly be caused by the upper trough and resultant convective instability.

Figure 18 compares $\operatorname{divU}$ and $\triangle \mathrm{EPT}$ with the lightning frequency distribution of case C. From 9 LT to 15 LT on

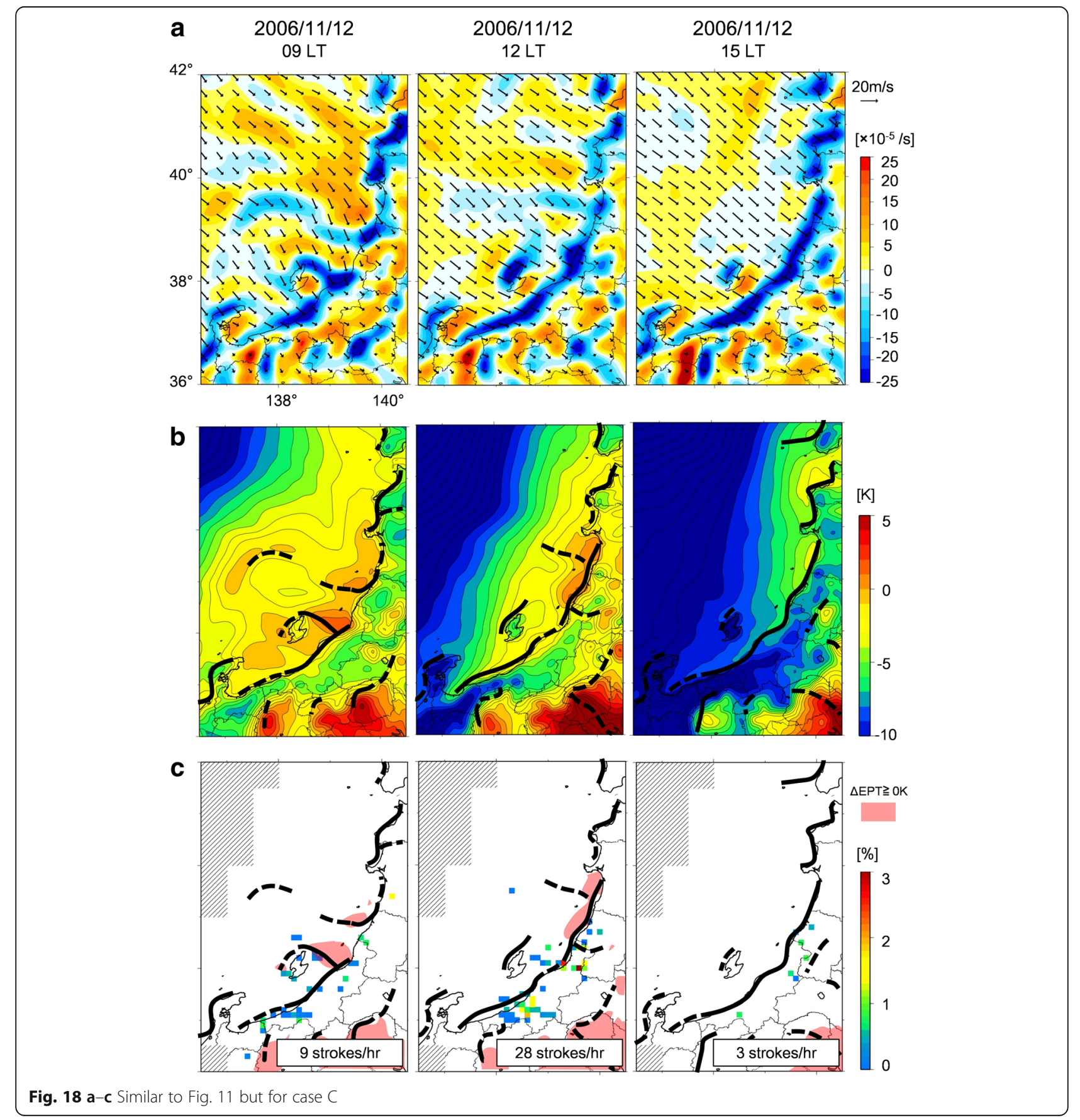




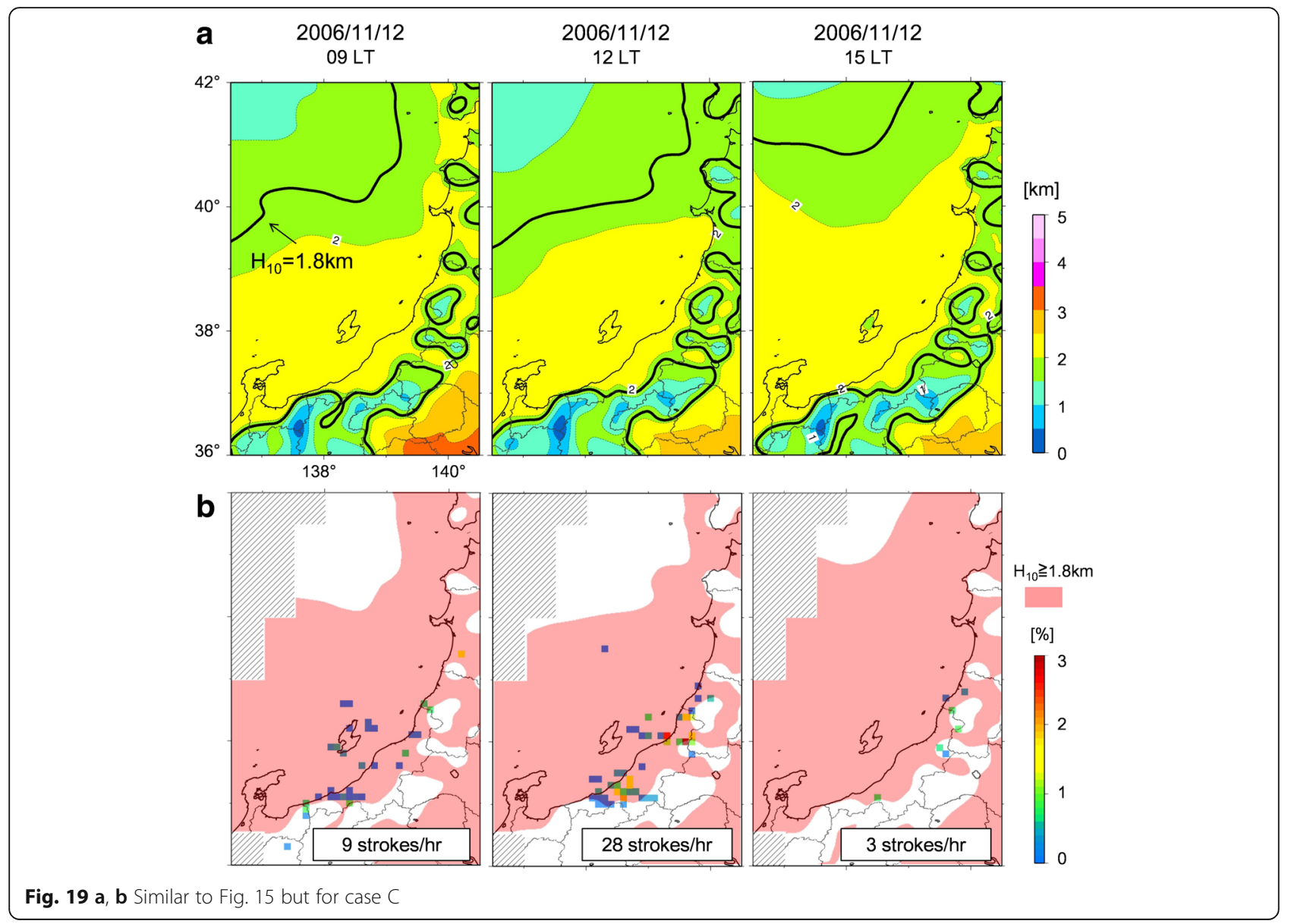

12 November, an unstable air mass appeared in the coastal areas of the Tohoku and Hokuriku districts as a result of the upper trough shown in Fig. 17. Additionally, due to northwesterly winds blowing over the Sea of Japan, topographic convergence lines were formed along the coastline. According to Fig. 18c, lightning strokes were distributed over the topographic convergence lines.

Figure 19 compares $\mathrm{H}_{10}$ and case C's lightning frequency distribution. As in case $\mathrm{B}$, relatively high $\mathrm{H}_{10}$ regions appear along the coastal areas of the Hokuriku district, indicating that these areas are more favorable for cloud electrification than other areas. Figure 19b shows that lightning mainly occurs in the coastal areas of the Hokuriku district, which is consistent with the distribution of $\mathrm{H}_{10}>1.8 \mathrm{~km}$.

\section{Case study summary}

Typical events of types A-C were selected (cases A, B, and $C$ ). These were examined based on analysis of surface weather charts and MSM-GPV data. The meteorological features of cases $\mathrm{A}-\mathrm{C}$ are summarized in Table 4.
The lightning frequency distribution of case A is mainly determined by the cold front that accompanied the SK cyclone.

The lightning frequency distributions of cases B and C, on the other hand, were mainly determined by topographic convergence and convective instability rather than by cold fronts. The difference between case A and case B could be the strength of the cold front. Figure 20 compares the vertical $p$-velocity values at $850 \mathrm{hPa}$ for case $\mathrm{A}$ and case $\mathrm{B}$. The updraft near the cold front is weaker in case $\mathrm{B}(-2$ to $-4 \mathrm{~Pa} / \mathrm{s})$ than in case $\mathrm{A}(-2$ to $-8 \mathrm{~Pa} / \mathrm{s})$.

Table 4 Case study summary

\begin{tabular}{|c|c|c|c|c|}
\hline Case & Type & Date (LT) & $\begin{array}{l}\text { Total lightning } \\
\text { frequency (stroke) }\end{array}$ & $\begin{array}{l}\text { Meteorological factors } \\
\text { determining lightning } \\
\text { frequency distribution }\end{array}$ \\
\hline A & $A$ & 2008/10/10-11 & 2336 & $\begin{array}{l}\text {-Cold front } \\
\text {-Topographic } \\
\text { convergence }\end{array}$ \\
\hline B & B & $2008 / 12 / 25$ & 973 & $\begin{array}{l}\text {-Topographic } \\
\text { convergence } \\
\text {-Unstable air mass }\end{array}$ \\
\hline C & C & 2006/11/12 & 153 & $\begin{array}{l}\text {-Topographic } \\
\text { convergence }\end{array}$ \\
\hline
\end{tabular}




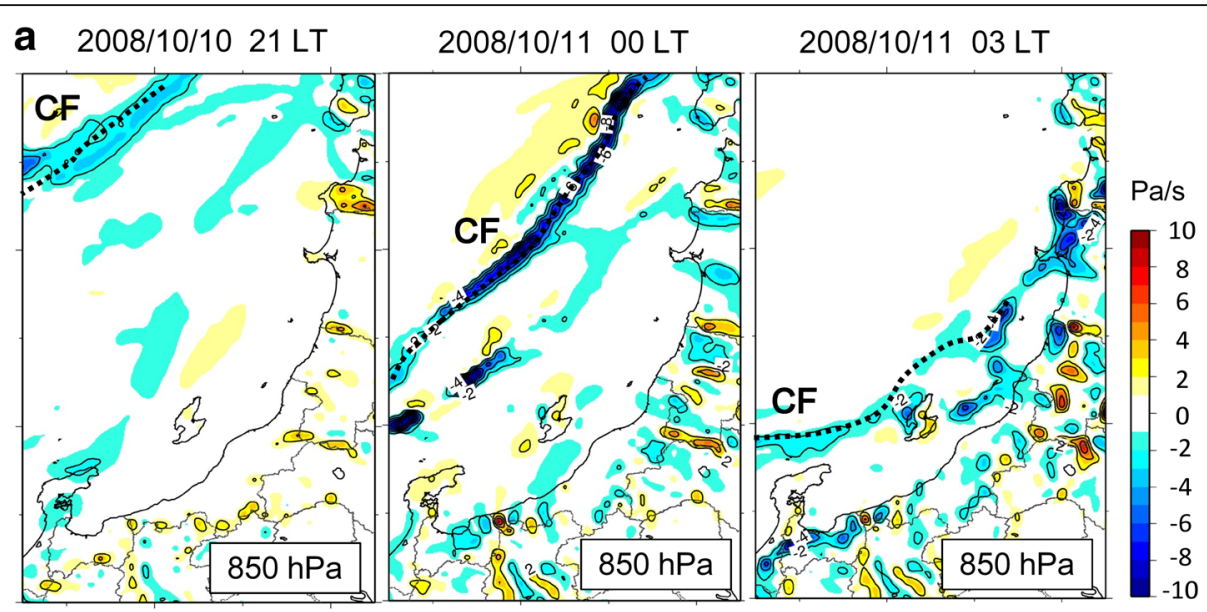

\section{b 2008/12/25 $09 \mathrm{LT} \quad 2008 / 12 / 2512 \mathrm{LT} \quad 2008 / 12 / 2515 \mathrm{LT}$}

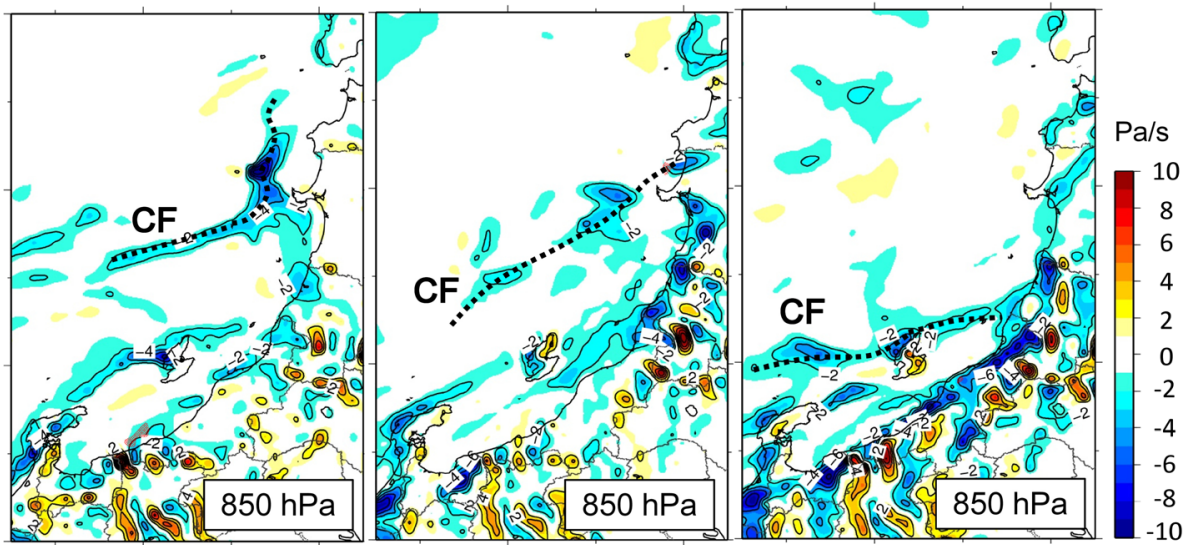

Fig. 20 a, b Comparison of vertical $p$-velocity (Pa/s) at 850 hPa for case A and case B. The vertical p-velocity data was obtained from MSM-GPV

Moreover, $\mathrm{H}_{10}$ distributions for cases $\mathrm{B}$ and $\mathrm{C}$ indicate that regions of high $\mathrm{H}_{10}$ tend to be confined to the coastal areas of the Hokuriku district, especially when a northwesterly wind dominates the study area. Considering that lightning mainly occurs within areas where $\mathrm{H}_{10}>1.8 \mathrm{~km}$, the results indicate that lightning frequency distributions in cases $\mathrm{B}$ and $\mathrm{C}$ may also correlate with the extent of the clouds' electrification.

\section{Possible mechanisms for seasonal changes in lightning frequency distribution}

Based on the cluster analysis and case studies, the seasonal changes in lightning frequency distribution (Fig. 4) could be explained as follows.

During the late autumn, lightning frequency distribution seems to be determined by cold fronts accompanying the SK or SJ cyclones. Since SK and SJ cyclones take the northernmost course of all cyclone types, the strong wind convergence line on the cold front may not reach the more southern Hokuriku district. Therefore, in late autumn, high lightning frequency is more often observed in the Tohoku district than in the Hokuriku district.

During the midwinter season, lightning frequency distributions may be more affected by topographic convergence than by cold fronts. Although this study did not examine in detail the mechanisms through which topographic convergences form, they may be induced by differences in surface roughness or elevation between land and sea areas and/or by thermally induced local winds (land breezes). Since midwinter topographic convergences are mostly formed by northwesterly winds blowing over the Sea of Japan, wind convergence becomes the strongest in the coastal areas of the Hokuriku district (since the wind blows perpendicular to the coastline there). Furthermore, northwesterly winds during the midwinter season tend to confine high $\mathrm{H}_{10}$ regions to the coastal areas of the Hokuriku district, which means that Hokuriku becomes an area where cloud electrification is most likely to occur. Therefore, midwinter lighting activity tends to concentrate near the coastline of the Hokuriku district. 
As mentioned above, this study suggests that midwinter lightning activity is more affected by topographic effects than that of the late autumn season. This fact was not made clear in previous studies, but statistical results presented by Lee et al. (2000) and Ishii et al. (2014) implied a similar tendency. Their results indicated that lightning frequency during the midwinter season shows a significant increase when the land breezes are strong.

Additionally, our study results indicate that the majority of WL cases are probably associated with cyclones passing the vicinity of the Japanese islands. However, it should be noted that previous studies concerning the meteorological conditions of winter lightning in Japan have indicated different results.

For example, Kitagawa (1996) claimed that approximately $60 \%$ of winter lightning in the coastal areas of the Sea of Japan (including the Kyushu, Chugoku, Kinki, Hokuriku, and Tohoku districts) is associated with cold air advection from the Siberian continent (advection lightning; type $\mathrm{C}$ ) rather than by cyclones. A similar result was obtained by Sugita and Matsui (2008), who based their research, which covers the Chugoku, Kinki, Hokuriku, and Tohoku districts, on the observational data of the JLDN.

One cause for this inconsistency may lie in the regional characteristics of the Tohoku district. According to Adachi and Kimura (2007), the offshore regions of the Tohoku district experience frequent wintertime cyclones. Therefore, lightning activity in our study area may be more strongly affected by cyclone activity than other regions in Japan. However, regional differences in meteorological factors affecting lightning activity need to be examined in future research.

\section{Conclusions}

This study identified three major types of Japanese winter lightning activity (types A-C) based on lightning frequency distribution and meteorological conditions. Detailed case studies were conducted for typical winter lightning cases (cases A-C) in order to examine the relationship between lightning activity and meteorological disturbances.

The results indicate that lightning frequency distribution during the late autumn is mainly determined by cold fronts accompanying extra-tropical cyclones (case A). On the other hand, midwinter lightning frequency distribution is determined by topographic convergence and convective instability rather than by cold fronts (cases $B$ and C). Finally, we found a few cases of advection lightning, whereas previous studies have regarded it as the dominant type of winter lightning activity in Japan. Although this inconsistency may be explained by regional features of our study area, further discussion and research are needed.

\section{Abbreviations}

CF: Cold front; CG: Cloud to ground; EOF: Empirical orthogonal functions; EPT: Equivalent potential temperature; GC: Ground to cloud; JLDN: Japan Lightning Detection Network; JMA: Japan Meteorological Agency; JPCZ: Japan sea Polar air mass Convergence Zone; LIDEN: LIghtning DEtection Network system; LLS: Lightning location system; LT: Local time; MSM-GPV: Meso-Scale Model Grid Point Value; WL: Winter lightning

\section{Acknowledgements}

We thank Tohoku Electric Power Company, Inc. for allowing us to use their lightning observation data. We also thank Dr. Masaki Sato, editor of Progress in Earth and Planetary Science, and peer reviewers for their thoughtful comments that helped us improve the manuscript. Generic Mapping Tools (GMT) were used for constructing figures.

\section{Funding}

Not applicable.

\section{Availability of data and materials}

The datasets supporting the conclusions of this article are included within the article.

\section{Authors' contributions}

DT and SK proposed the topic and conceived and designed the study. $\mathrm{NH}$ operated the lightning location system (LLS) and created the lightning stroke datasets. All authors have read and approved the final manuscript.

\section{Competing interests}

The authors declare that they have no competing interests.

Consent for publication

Not applicable.

\section{Publisher's Note}

Springer Nature remains neutral with regard to jurisdictional claims in published maps and institutional affiliations.

\section{Author details}

${ }^{1}$ IDEA Consultants, Inc., Hayabuchi 2-2-2 Tsuzuki, Yokohama 224-0025, Kanagawa, Japan. ${ }^{2}$ Graduate School of Environmental Studies, Tohoku University, Aoba 6-3 Aramaki Aoba, Sendai 980-8678, Miyagi, Japan. ${ }^{3}$ R\&D Center of Tohoku Electric Power Company, Inc, Nakayama 2-1 Aoba, Sendai 981-0952, Miyagi, Japan.

Received: 10 April 2016 Accepted: 8 March 2017

Published online: 27 March 2017

\section{References}

Adachi S, Kimura F (2007) A 36-year climatology of surface cyclogenesis in East Asia using high-resolution reanalysis data. SOLA 3:113-116

Brook M, Nakano M, Krehbiel M, Takeuti T (1982) The electrical structure of Hokuriku winter thunderstorms. J Geophys Res 87:1207-1215

Cummins KL, Murphy MJ, Bardo EA, Hiscox WL, Pyle RB, Pifer AE (1998) A combined TOA/MDF technology upgrade of the U.S. National Lightning Detection Network. J Geophys Res 103:9035-9044

Fujisawa G, Kawamura R (2005) Recent tendencies of winter thunderstorms in the Hokuriku district and associated atmospheric conditions. TENKI 52:13-24 (in Japanese)

Hojo J, Ishii M, Kawamura T, Suzuki F (1989) Seasonal variation of cloud-toground lightning flash characteristics in the coastal areas of the Sea of Japan. J Geophys Res 94:13207-13212

Honma N (2012) Performance of the Tohoku IMPACT sensor network in winter lightning detection. IEEJ Trans PE 132(6):579-587

Honma N, Suzuki F, Miyake Y, Ishii M, Hidayat S (1998) Propagation effect on field waveforms in relation to time-of-arrival technique in lightning location. J Geophys Res 103:14141-14145

Honma N, Cummins KL, Murphy MJ, Pifer AE, Rogers T (2012) Improved lightning locations in the Tohoku region of Japan using propagation and waveform onset corrections. IEEJ Trans PE 133(2):195-202 
Ishii M, Saito M, Chihara M, Natsuno D (2012) Transferred charge and specific energy associated with lightning hitting wind turbines in Japan. IEEJ Trans PE 132(3):294-295

Ishii K, Hayashi S, Fujibe F (2014) Statistical analysis of temporal and spatial distributions of cloud-to-ground lightning in Japan from 2002 to 2008. J Atmos Electr 34(2):79-86

Kitagawa N (1996) Meteorological aspects of winter thunderclouds along the Japan Sea coast. TENKI 43:7-17 (in Japanese)

Kitagawa N, Michimoto K (1994) Meteorological and electrical aspects of winter thunderclouds. J Geophys Res 99:10713-10721

Lee J, Wada M, Kawasaki Z, Matsuura K, Takeuchi M, Sonoi Y (2000) Lightning activity during winter thunderstorm season observed by SAFIR. Electr Eng Jpn 132(1):811-817

Michimoto K (1993) A study of radar echoes and their relation to lightning discharges of thunderclouds in the Hokuriku district part II: observation and analysis of "single-flash" thunderclouds in midwinter. J Meteor Soc Jpn 71(2): $195-204$

Ohigashi T, Tsuboki K (2005) Structure and maintenance process of stationary double snowbands along the coastal region. J Meteor Soc Jpn 83(3):331-349

Rakov VA, Uman MA (2007) Lightning: physics and effects. Cambridge University Press, Cambridge

Sugita A, Matsui M (2008) Examples of winter lightning observed by the JLDN. In: Abstracts of 20th International Lightning Detection Conference, Tucson, Arizona, 21-23 April 2008.

Sugita A, Matsui M (2012) Lightning characteristics in Japan observed by the JLDN from 2001 to 2010. In: Abstracts of 22nd International Lightning Detection Conference, Broomfield, Colorado, 2-3 April 2012.

Takahashi T (1984) Thunderstorm electrification-a numerical study. J Atmos Sci 41:2541-2558

Tsurushima D, Sakaida K, Honma N (2014) Climatological features of winter lightning activity in the coastal areas of Sea of Japan, Tohoku and Hokuriku district. Quart J Geogr 65:189-206 (in Japanese with English abstract)

\section{Submit your manuscript to a SpringerOpen ${ }^{\circ}$ journal and benefit from:}

- Convenient online submission

- Rigorous peer review

- Immediate publication on acceptance

- Open access: articles freely available online

- High visibility within the field

- Retaining the copyright to your article

Submit your next manuscript at $\boldsymbol{s p r i n g e r o p e n . c o m ~}$ 